\title{
Diseño y construcción de un paraguas plegable para espacios arquitectónicos
}

\author{
Design and construction of a folding umbrella for architectural spaces \\ Desenho e construção de um guarda-chuva dobrável para espaços arquitetônicos
}

\section{Carlos César Morales-Guzmán}

Universidad Veracruzana, Poza Rica, Veracruz (México)

Facultad de Arquitectura

Morales-Guzmán, C. C. (2019). Diseño y construcción de un paraguas plegable para espacios arquitectónicos. Revista de Arquitectura (Bogotá), 2/(I), 76-89. doi: http://dx.doi.org/10.14718/RevArq.2019.21.I.1623

\author{
Arquitecto, Universidad Veracruzana (México). \\ Maestro en Diseño Arquitectónico y Bioclimatismo, Universidad \\ Cristóbal Colón (México) \\ Máster en Ingeniería para la Arquitectura, Universidad Camilo José \\ Cela (España) \\ Doctor en Arquitectura, Universidad Nacional Autónoma de México \\ (México). \\ Doctor en Estructuras de la Edificación, Universidad Politécnica de \\ Madrid (España). \\ Posdoctorado en Arquitectura Tensada, Universidad Politécnica de \\ Catalunya (España). \\ Posdoctorado en Ingeniería y Arquitectura Transformable, Universi- \\ dad de Sevilla (España). \\ (DD http://orcid.org/0000-0002-4499-6968 \\ dr.arqmorales@gmail.com / carlmorales@uv.mx
}

\section{Resumen}

El desarrollo de esta investigación culmina en un prototipo experimental realizado por la síntesis metodológica del diseño experimental, para lo cual se consideraron como referencia los sistemas plegables. Este concepto se llevó a cabo en el proceso del prototipo de paraguas plegable. Dicha modelación tuvo como referentes históricos el teatro ambulante del arquitecto Emilio Pérez Piñero, el cual se fundamenta en el principio de una estructura plegable, y Leonardo Da Vinci, quien creó un sistema de estructuras recíprocas que desarrolló por medio de esquemas constructivos y manifiestos. Siguiendo estos conceptos se creó el prototipo, con el manejo del software WinTess, donde se calculó la estructura portante y la membrana de dicho modelo propuesto. Lo más destacado fue el proceso de construcción de este prototipo, con lo cual se generó nuevo conocimiento técnico en cuanto a la simulación y fabricación de sistemas plegables y transformables, que tienen la capacidad de plegarse, moverse y erigirse en otro lugar.

Palabras clave: arquitectura plegable; arquitectura transformable; detalles constructivos: modelo experimental; simulación estructural en 3D; tensoestructuras.

\begin{abstract}
This research culminates in an experimental prototype, carried out through the methodological synthesis of the experimental design, for which folding systems were considered as a reference point. This concept was developed through a folding umbrella prototype. Said modeling had two historical referents: the itinerant theater of architect Emilio Pérez Piñero, based on the principle of a folding structure, and Leonardo Da Vinci, who created a system of reciprocal structures using constructive and manifest schemes. Following these concepts, the prototype was developed using the Witness software, where the supporting structure and the membrane were calculated. The highlight of the construction of this prototype was the assembly process, carried out with the help of undergraduate and graduate students, which generated new technical knowledge on the simulation and manufacturing of folding and transformable systems.
\end{abstract}

Keywords: folding architecture; transformable architecture; experimental model; 3D structural simulation; constructive details; tense structures.

\section{Resumo}

O desenvolvimento desta pesquisa culmina num protótipo experimental realizado pela síntese metodológica do desenho experimental, para o qual foram considerados como referência os sistemas dobráveis. Esse conceito foi realizado no processo do protótipo de guarda-chuva dobrável. Essa modelação teve como referentes históricos o teatro ambulante do arquiteto Emilio Pérez Piñero, o qual está fundamentado no princípio de uma estrutura dobrável, e Leonardo $\mathrm{Da}$ Vinci, que criou um sistema de estruturas recíprocas desenvolvido por meio de esquemas construtivos e manifestos. A partir desses conceitos, o protótipo foi criado com o auxílio do software Witness, com o qual foi calculada a estrutura portadora e a membrana do modelo proposto. Destacou-se o processo de construção desse protótipo, com o qual foi gerado novo conhecimento técnico quanto à simulação e fabricação de sistemas dobráveis e transformáveis, que têm a capacidade de dobrar-se, mover-se e levantar-se em outro lugar.

Palavras-chave: arquitetura dobrável; arquitetura transformável; detalhes construtivos; modelo experimental; simulação estrutural em 3D; tensoestruturas.

\section{Introducción}

El resultado de investigación que se presenta en este artículo es la fase final de un modelado experimental de un sistema plegable que se publicó en esta misma revista (Morales-Guzmán, 2016, pp. 98-110). En dicho artículo se explicó la metodología experimental, la cual partió de una fase conceptual y concluyó con un prototipo a escala 1:1. Asimismo, se explicaron las bases de cómo desarrollar una estructura plegable en el diseño arquitectónico, y qué procesos conceptuales se deberían seguir para desarrollar sistemas plegables (el diseño por modelación es una de las principales guías para desarrollar estos sistemas, ya que se verifican los movimientos y la sistematización de las piezas que posteriormente se tienen que construir, y ayuda a que posteriormente la geometría se adecue a los errores encontrados en los modelos). En esta fase se demostró cómo el procedimiento metodológico anterior mejora la estructura funcionalmente, y se comprobó que puede tener utilidad para los espacios arquitectónicos abiertos como los lugares públicos (parques, plazas, escenarios, etc.). Esta inquietud se produce por la aparición de materiales eficientes, ligeros y de alta resistencia que se utilizan en la actualidad, que brindan la posibilidad de reducir los espesores de la estructura de esta construcción hasta llegar al prototipo final (p. 98).

Un ejemplo del continuo avance de la tecnología en las estructuras se observa cuando se utilizan materiales cuyo peso propio y rigidez son casi nulos en la estructura, pero su trabajo actúa bajo una lógica estructural que los hace poco deformables, aun estando expuestos a cargas externas. Dicha teoría era sustentada por el arquitecto Frei Otto en sus investigaciones de superficies mínimas, la cual aplicó en el pabellón alemán 
de la Feria Mundial de 1967. Esta resistencia se logra bajo la optimización de la forma en las estructuras, encontrando aquellas que favorezcan el equilibrio estructural en la geométrica, a fin de mejorar la distribución de los esfuerzos. En el caso de la presente investigación, se evocan sistemas transformables, con capacidad de plegarse, moverse y erigirse en otro lugar.

En consecuencia, se presenta en breve una línea de tiempo que servirá de antecedente, en donde se señalan ciertos momentos históricos importantes en la arquitectura transformable. Se inicia con la invención del sistema de unión tipo tijera, el cual permitió la movilidad dentro de la estructura; este factor justifica esta exploración, la cual pretende desarrollar nuevo conocimiento para la enseñanza y, en especial, para el desarrollo geométrico de las estructuras plegables, ya que esta es una de las medidas fundamentales para las aproximaciones metodológicas del diseño del paraguas plegable.

Por lo tanto, en esta investigación se plantea desarrollar el prototipo para reactivar espacios públicos urbanos en zonas cálidas en el estado de Veracruz (México), ya que dicha región tiene una extensión territorial costera con alta temperatura, por lo que un sistema plegable fácil de montar en el sitio hace necesario que se utilicen cubiertas ligeras de rápido montaje; por esta razón, el desarrollo de la estructura se orienta a generar una tecnología de construcción de rápido montaje; por la naturaleza del proyecto se realizan varios pasos que se publicaron anteriormente (Morales, 2016, pp. 99-101), y para esta última fase solo se mencionarán los más relevantes, estos son: la modelación, el prototipo, la aproximación del modelo a escala real, y la construcción final del producto.

\section{Antecedentes $^{1}$}

Para justificar la ruta de investigación se resume una línea de tiempo en la que se señalan tres periodos dentro la historia que son importantes para el proceso de este proyecto como referencia conceptual, esto sustenta y aclara qué tipo de virtudes debe tener un sistema plegable.

Flexibilidad. En el primer periodo se encuentra que los beduinos fueron de los primeros en utilizar materiales textiles para autoconstruir sus espacios provisionales, dicho sistema era fácil de transportar (Figura 1) y tenía aplicaciones funcionales y prácticas, ya que se podía montar fácil-

1 Estos antecedentes se encuentran en Morales-Guzmán (2016, pp. 99-100), y se consideran relevantes para comprender el origen de la propuesta.

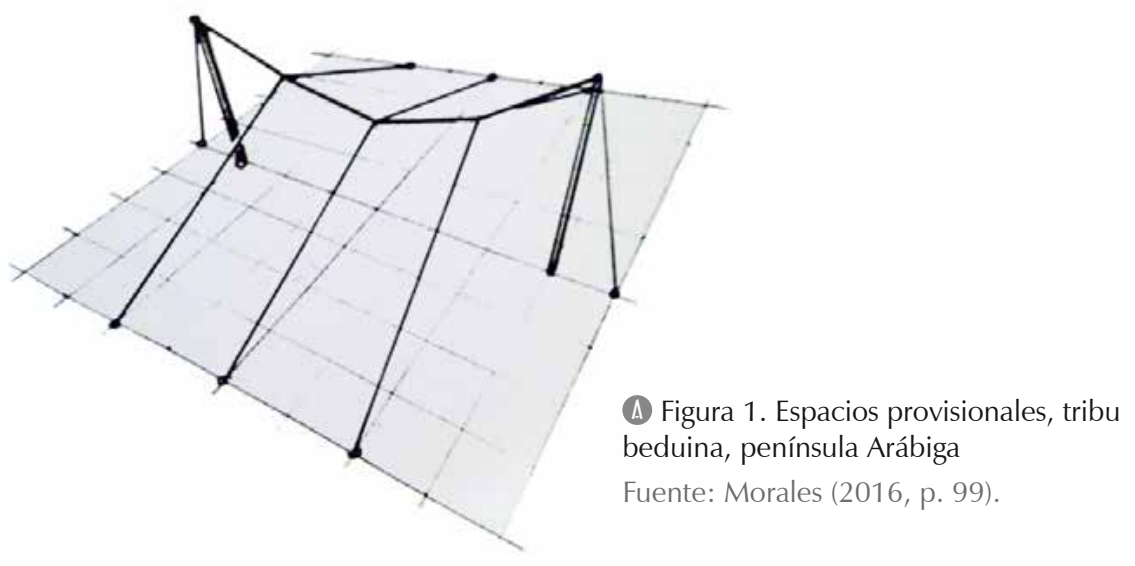

mente en cualquier lugar y tener así un espacio para habitar. Esto indica la importancia de que la estructura sea flexible para integrarse a otros requerimientos arquitectónicos.

Prefabricación. En el segundo periodo se encuentra el uso de la forma como estructura. Con la aparición de los materiales más resistentes y ligeros surgieron inmensidad de prototipos industrializados que facilitaron construir espacios en muy poco tiempo. Más tarde aparecieron el arquitecto Emilio Pérez Piñero, con su teatro ambulante plegable en el Concurso Internacional de la Unión Internacional de Arquitectos en 1961, y el ingeniero Fuller, con su geodésica desmontable en 1963 en la Feria Mundial de Montreal; cada uno de ellos son sistemas óptimos para construir espacios de grandes dimensiones (Figura 2). Estas aplicaciones demuestran que un sistema industrializado bien diseñado sirve para varias funciones.

Transformación. En el último periodo se encuentra que las estructuras transformables toman la habilidad de transmutar su entorno espacial, esto lo demanda la sociedad actual, ya que necesitan espacios multifuncionales. En la actualidad se desarrollan muy pocos modelos transformables debido a su complicada manufacturación y análisis estructural, por lo cual casi no se confeccionan este tipo de estructuras. En esta área de investigación y desarrollo surge el doctor Félix Escrig, quien realiza estructuras plegables de forma eficiente y aplicada. Un ejemplo de estas es la cubierta del Polideportivo de Sevilla construida en 1994 (Figura 3).

Esta investigación se beneficia de la línea de tiempo analizada a profundidad para desarrollar las siguientes experimentaciones y formalizar una serie de pasos que ayudarán al proyecto final, y a justificar el desarrollo de diseño en el que se obtendrá su forma y la aplicación constructiva de sus detalles estructurales (Morales, 2013a, 2014a, 2015, 2016).

This article is available in English on the website of Revista de Arquitectura (Bogotá)

doi: http://dx.doi.org/10.14 718/RevArq.2019.21.1.1623

Design and construction of a folding umbrella for architectural spaces 

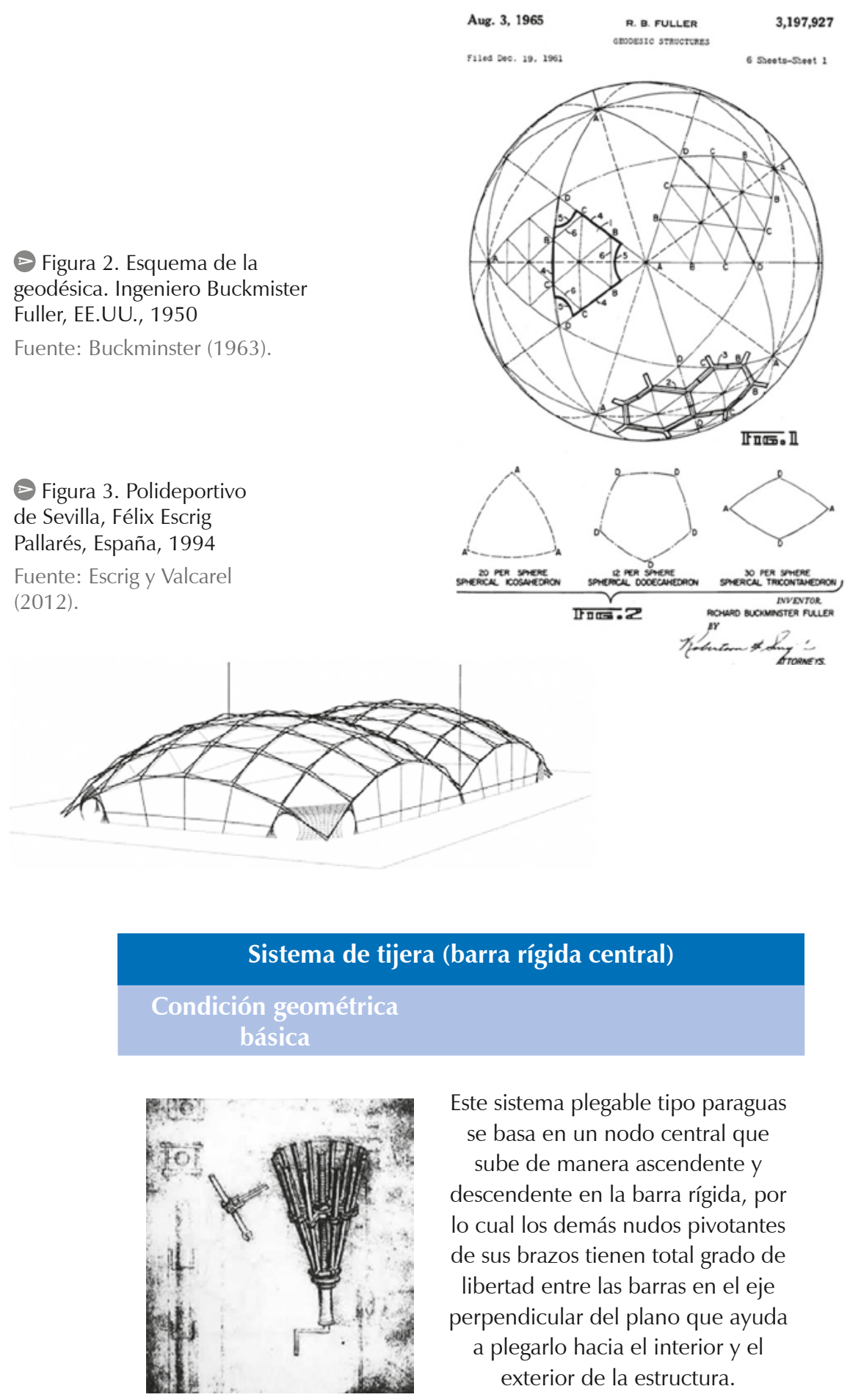

Este sistema plegable tipo paraguas se basa en un nodo central que sube de manera ascendente $y$ descendente en la barra rígida, por lo cual los demás nudos pivotantes de sus brazos tienen total grado de libertad entre las barras en el eje perpendicular del plano que ayuda a plegarlo hacia el interior y el exterior de la estructura.

A Tabla 1. Forma básica para generar una estructura plegable

Fuente: Rodríguez (2005) y Morales (2016, p. 101).

\section{Metodología}

El desarrollo de este proyecto comienza por la experimentación de la forma del paraguas, esto facilita la generación de un sistema de diseño que pueda transformar el espacio en la arquitectura. La morfología del modelo se justifica en generar una estructura plegable tipo paraguas, con una tenso-estructura hiperbólica con la propiedad de plegarse; con esta característica se desarrolla el diseño, por medio de iteraciones de movimiento en su estructura. Este modelo servirá para la recuperación de espacios urbanos y de protección para las inclemencias del clima en la región y el estado de Veracruz (México). A fin de entender lo que se hará, se recordará una de las primeras fases del proyecto: la modelación. Al comienzo se experimentó con tres modelos tipo tijeras, cada experimento tuvo un principio conceptual matemático el cual se geometrizó, pero para este caso solo se estudiará el modelo que generó mayor optimiza- ción en el plegado y facilidad de fabricación en sus partes; la metodología extendida se puede apreciar en el artículo anterior publicado bajo el nombre: "Construcción experimental de un sistema transformable tensado plegable" (Morales, 2016, pp. 98-110), en donde se desarrolla toda la serie de modelos de movimiento de las estructuras plegables tipo paraguas.

La forma de este tipo de estructura se generó bajo el esquema que se muestra en la Tabla 1, con los bocetos básicos que debería tener una estructura plegable; si no se contempla este principio, la flexibilidad dentro de la estructura no se dará; una vez comprendido esto, se podrá reproducir un anteproyecto de sistema plegable, que producirá la propuesta final.

La pauta para crear elementos de forma simple y con más funcionalidad se enfatizó en el modelado experimental que se explicó en el mencionado artículo (Morales, 2016), en el cual se desarrolló una serie de pasos y modelos experimentales que sirvieron para obtener la forma final del proyecto y su resolución constructiva en esta investigación; esto implicó buscar soluciones óptimas que brindaran la simplicidad del modelo, con la finalidad de determinar las características que se establecen en el proceso de este trabajo, por ello la experimentación en la investigación tuvo un papel muy importante para desarrollar la metodología por medio de la modelación, la cual generó un modelo a escala 1:5 para ver los detalles de conexión constructiva del paraguas plegable (explicada con detenimiento en Morales, 2016). Debido a que era importante para el proyecto la manera como se desarrollarían las articulaciones y conexiones del sistema se enfatizó el modelado en la plegabilidad de la estructura, por ello era conveniente crear el modelo con materiales que tuvieran la resistencia adecuada a la tracción, ya que la tenso-estructura (velaría) hace que se rigidicen los miembros estructurales de la estructura (Figuras 4 a 7), por ello se realizó un nodo móvil ascendente que alberga los ocho miembros articulados, estos a su vez se articulan nuevamente a un tercio de su claro para conectar otros miembros tubulares que se conectan en el nodo superior fijo que ayuda a sostener la plegabilidad del sistema retráctil. Posteriormente se coloca un accesorio de refuerzo para conectar las articulaciones de la linternilla de la velaría, que a su vez también se fija con cables para que la articulación colocada en la unión metálica del paraguas tenga un tope; en consecuencia, se coloca un sistema de poleas que actúa como palanca para subir el nodo ascendente a fin de plegar la estructura de la vela y así mantener rígido el sistema estructural.

Ya colocada la velaría en la parte superior de la estructura, se ponen tensores reguladores en las uniones metálicas de los bordes tubulares para tensar las relingas en los apoyos extremos de los miembros, con ello se equilibra el sistema estructural de la estructura transformable. En seguida se prueba la velaría de la estructura con el sistema de poleas (Figuras 8 y 9) y se observa cómo el desarrollo de la tenso-estructura es estable y 


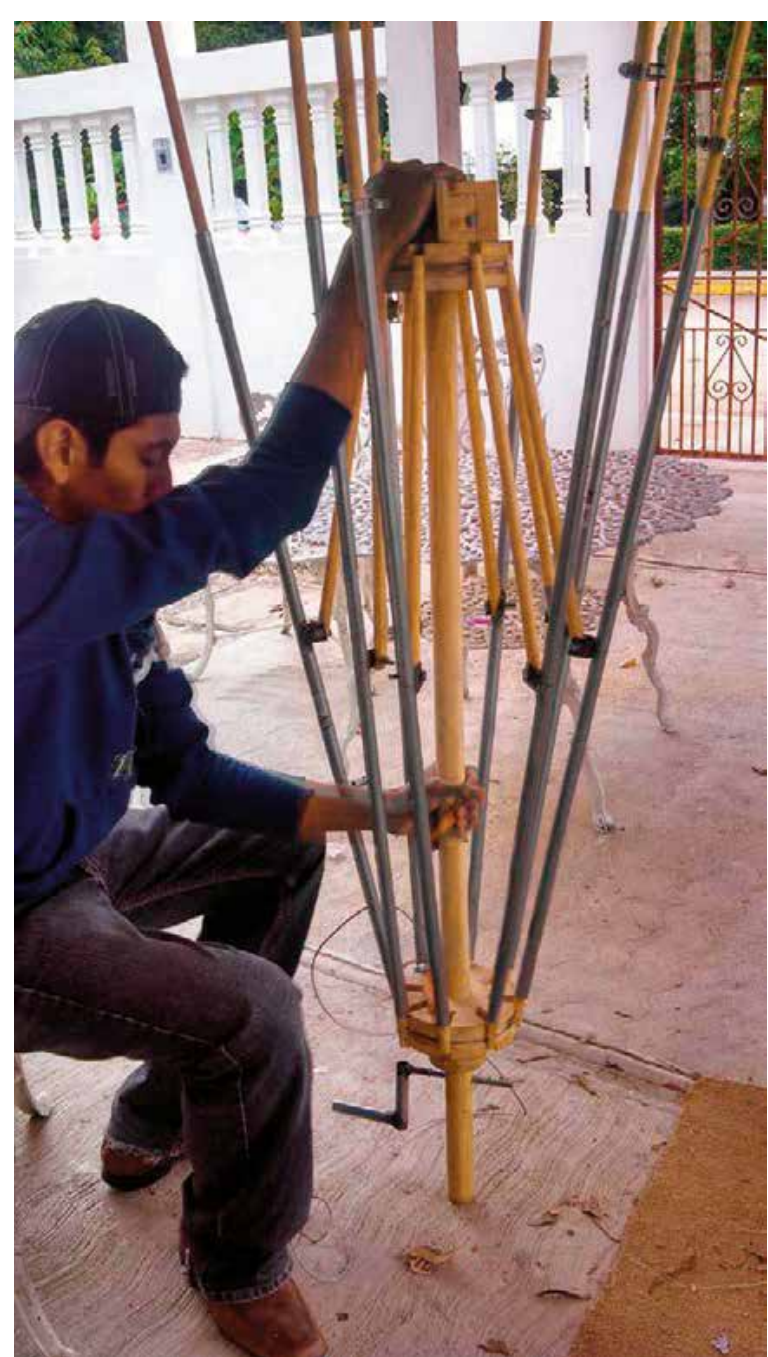

conserva una figura estructural adecuada para mantener el equilibrio de las tensiones dentro de su superficie. Una parte importante de esa reagudización de la velaría es el regulador de los bordes, por ello se puede plegar el manto del paraguas; es importante mencionar que este paso proporcionó los detalles constructivos que se realizarán más adelante y la manera como se comportarían en principio dichas conexiones. Aunque el material era muy diferente, al igual que su resistencia, este modelado escalado ayudó a entender y determinar las conexiones finales del proyecto (Morales, 2013b, 2014b y 2016).

\section{Resultados}

\section{Desarrollo del prototipo experimental}

En este apartado se abordará el proceso de manufactura del prototipo de los miembros de la estructura, ya que esta construcción tuvo un papel importante en la fase final del proyecto, por ello se determinó que el prototipo tendría un poste central de A36 de OCE $89 \mathrm{~mm}$, que soportaría la tensión de las cargas de los brazos a fin de atender las cargas solicitadas. También se fabricó el armado de piezas, las uniones de cumbrera y nodo deslizante, y se situó en los miembros secundarios plegables un OCE $60 \mathrm{~mm}$, así como los de la cumbrera que auxilian la transformación del paraguas; las placas de cumbrera y nodo deslizante se soldaron a las uniones; este
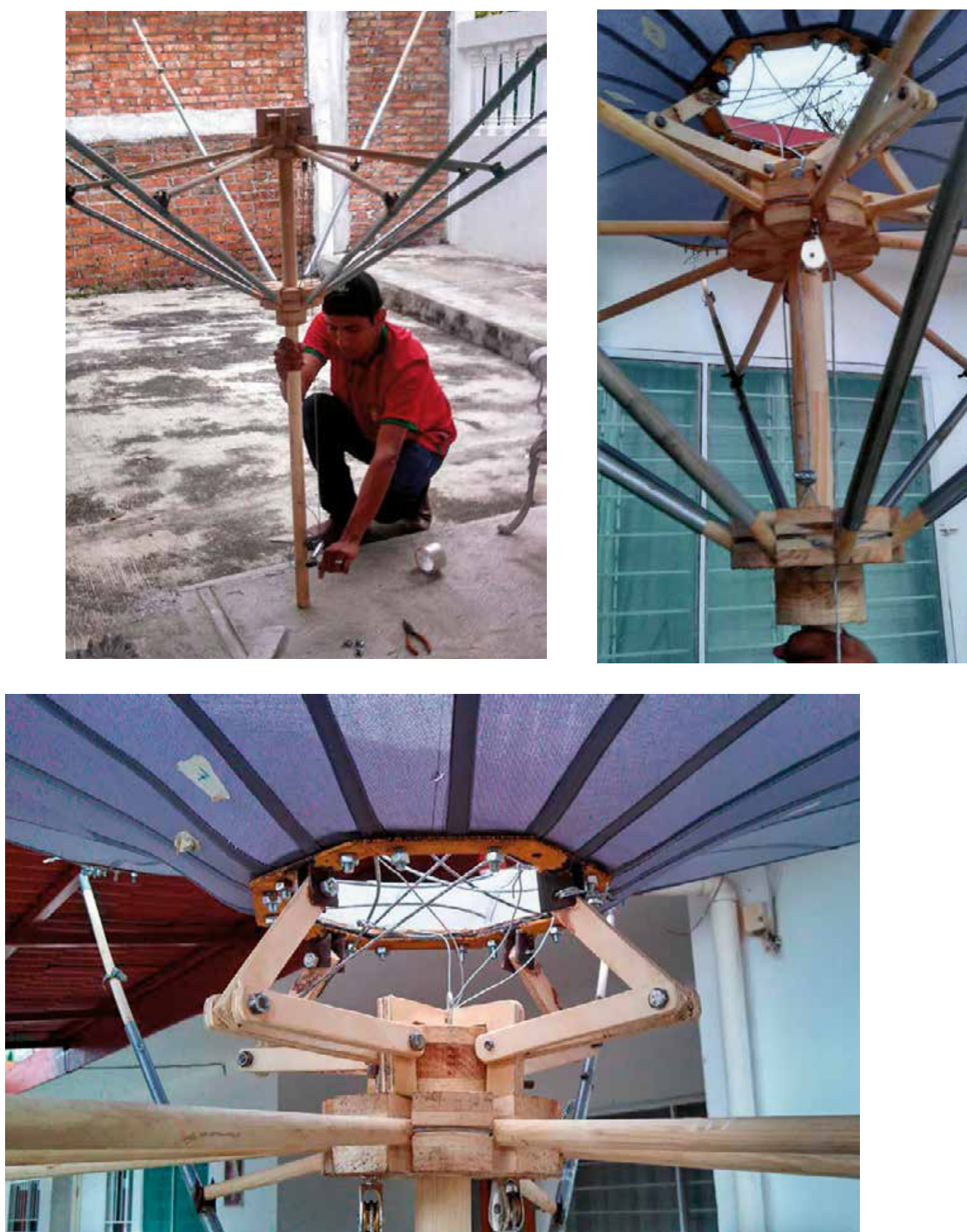

mismo método se aplicó a la manufactura de la base del poste central. Previamente, se construyó un pedestal que soportara el nodo deslizante, en este se instalaron las medidas justas de este nodo articulado, para lo cual se efectuaron varias soldaduras de placa en donde se colocarían los mecanismos que articularían la estructura y, posteriormente, le darían la facilidad de plegarse.

Después de fabricar varias piezas compuestas (Figuras 10 a 13) que ayudaron principalmente al sistema plegable, se realizó un primer montaje para verificar el plegado de la estructura; en paralelo, se desarrolló una cimentación de $0,80 \mathrm{~m} \times 0,80 \mathrm{~m}$, con un dado de $0,40 \mathrm{~m}$ y una altura de $1,20 \mathrm{~m}$. Se le instaló una placa de acero de $1 / 2 "$, incrustada al dado, que recibiría el poste central. Durante el proceso se colocó la membrana textil (Figuras 14 a 17), en la instalación se presentaron inconvenientes en el tensado y se tuvieron que seccionar los miembros secundarios de la estructura y la membrana tensada, lo que redujo la estructura a un diámetro de $5 \mathrm{~m}$; dichos inconvenientes servirían de experiencia para realizar la fase final del prototipo (Morales, 2013b, 2014b, 2016, 2017).
(A) Figuras 4 a 7. El modelado del paraguas retráctil ayudó a generar detalles constructivos más exactos para su funcionamiento al desplegado

Fuente: Morales (2012; 2016, fig. 16). 


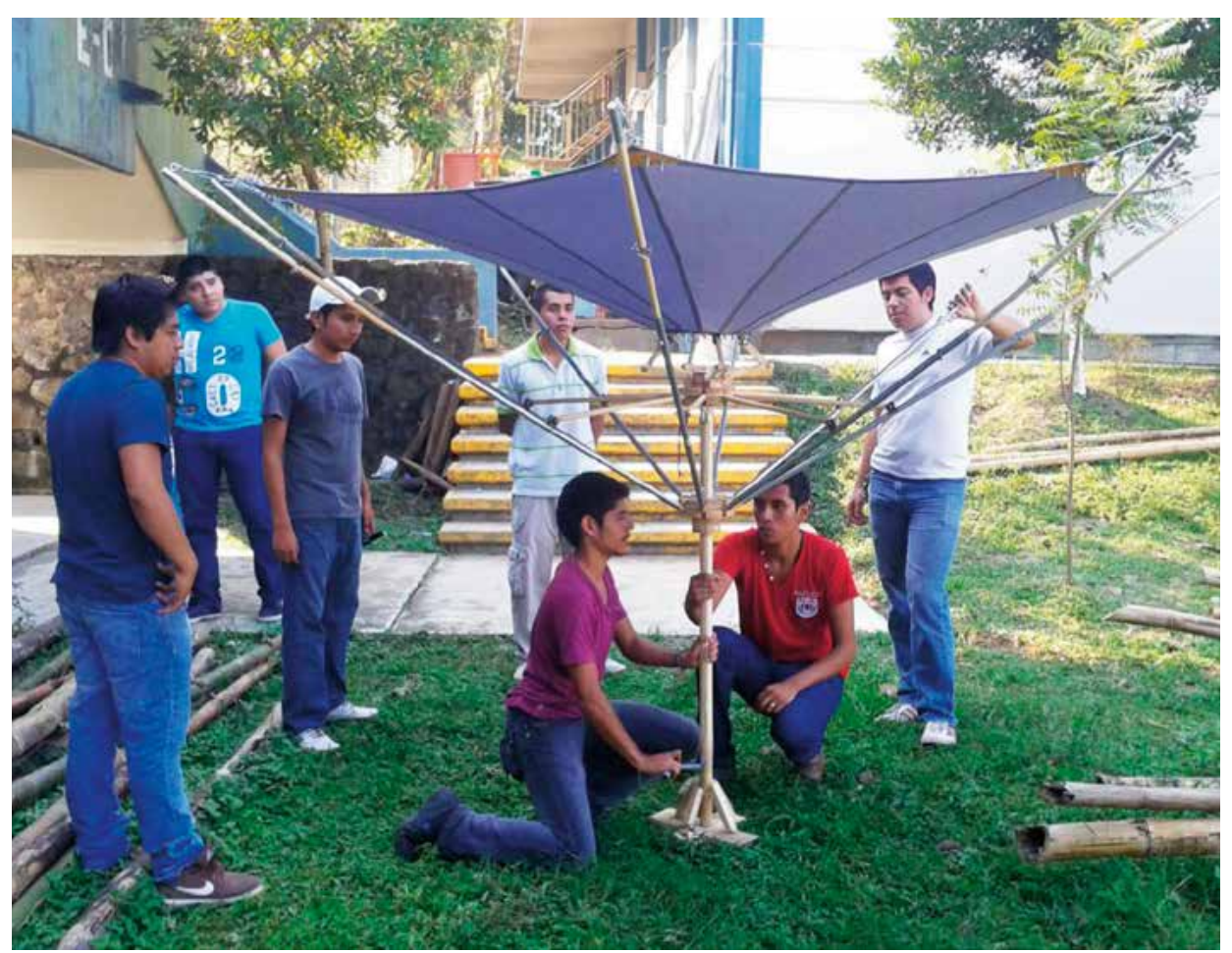

(A) Figuras 8 y 9 .

El desplegado del modelo ayudó a formar conceptos constructivos del movimiento del sistema plegable del paraguas

Fuente: Morales (2013b; 2016, fig. 17).

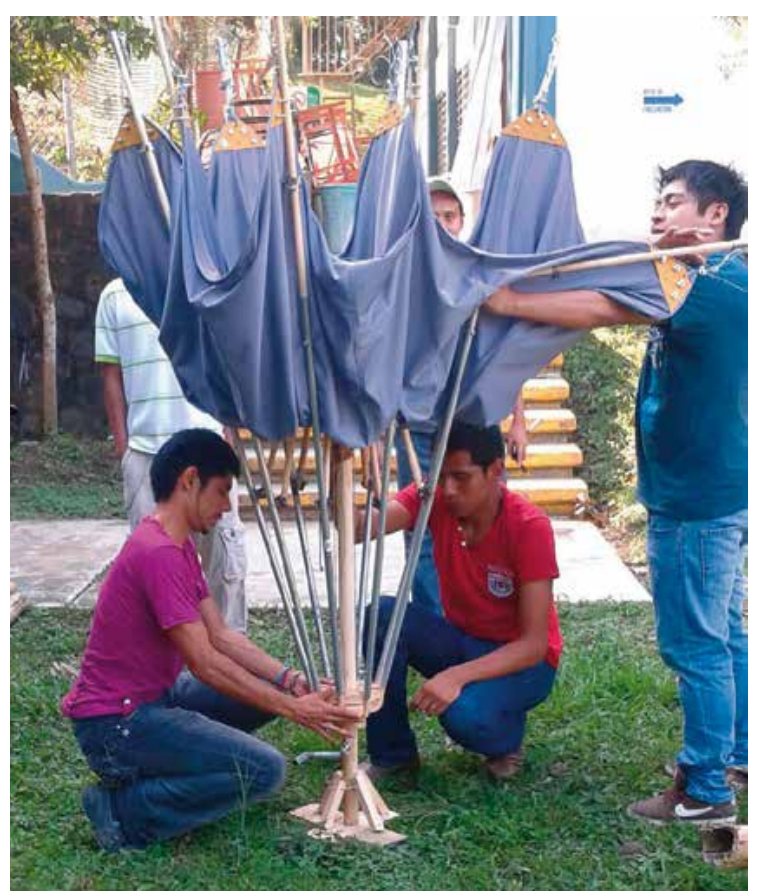

\section{Alcances y mejoras}

\section{Mejoramiento final del proyecto}

A partir de los desarrollos alcanzados, se da inicio a la fase de mejoramiento y alcances reales del prototipo final. Como se señaló, el modelo anterior ayudó a verificar el método de ensamble y construcción de un paraguas transformable, en este periodo se mejorarán los percances anteriores, como el error de la membrana -quedó más corta y no alcanzó a desplegar todo el diámetro propuesto-. Como primera medida, se recalculó el análisis estructural del paraguas plegable con un diámetro de 15,5 m; posteriormente a este análisis se realizó la selección del material para construir dicho proyecto (tabla 2), se comprobó con el análisis matricial del programa WinTess, y este se comparó con el cálculo para el modelo experimental anterior. Se anotaron las diferencias de análisis de la estructura anterior y se reconfiguraron los miembros estructurales del paraguas plegable; los miembros se calcularon por el método del Bridge Design Manual, del Load and Resistance Factor Design (LRFD), el cual arrojó un perfil de acero A36, con un tubo principal de $152 \mathrm{~cm}$ de perfil; los miembros secundarios fueron de $75 \mathrm{~cm}$ de perfil, las uniones se hicieron de placas metálicas de $1 / 4^{\prime \prime}$, con una soldadura de arco eléctrico con isótopo EXX60 estructural; en consecuencia, se calcula la superficie de la membrana del paraguas plegable (Tabla 3), donde se verifica una membrana Serge Ferrari T1002, el factor de seguridad ofrece un óptimo resultado; en dicho análisis también se da un resultado de medidas para las religas que en este caso es un cable de $18 \mathrm{~mm}$, con acostillamientos de la misma medida.

Posteriormente se realizaron los detalles estructurales del paraguas plegable, una de las mejoras es la unión articulada ascendente que ayuda a que la estructura se transforme, en ella se colocan poleas de carga de $3 \mathrm{t}$, con un cable de $12 \mathrm{~mm}$ de espesor para cargar los miembros secundarios del paraguas (Figuras 18 a 24); estas se regulan con un malacate de $3 \mathrm{t}$ en la parte inferior, manejada con una manivela que cada vez que se le dan vueltas pliega y despliega la estructura. En los brazos principales de despliegue se propusieron postes metálicos en posición vertical, para generar una figura triangular, con dicho diseño se crea una viga y un poste cable (Figuras 25 a 27), esto proporciona mayor inercia en el material y relaja la tensión de los esfuerzos que se generan en los brazos cuando se despliegan. En consecuencia, en los brazos principales se colocaron articulaciones para que los miembros de la cabecera interior del paraguas tuvieran la propiedad de plegar (Figuras 28 a 33), también se realizaron los detalles de las uniones con la membrana cerca de la frontera del poste cable, y en el poste central; este detalle en especial ayudará a que la membrana esté rígida pero a la vez flexible para no generar momentos en superficie (Reglamento de construcción del Distrito Federal - RCDF) (Morales, 2012, 2013, 2014, 2017).

\section{Proceso constructivo del paraguas plegable}

A fin de entender la construcción final de ese proyecto se realizará una recapitulación de todo lo generado anteriormente, por lo cual se puede observar que la aplicación de paraguas plegable invertido es viable para una aplicación real, en este caso de estudio se selecciona la cafetería de la Facultad de Arquitectura para izar este modelo. El primer paso fue la manufactura del poste principal con un acero A36 de $152 \mathrm{~cm}$ de perfil y $6 \mathrm{~mm}$ de cara interior; a este se le fabricó un pedestal de un tubo de acero de $61 / 2 "$ con placas de $1 / 4^{\prime \prime}$ a fin de armar el nodo deslizante del paraguas; 

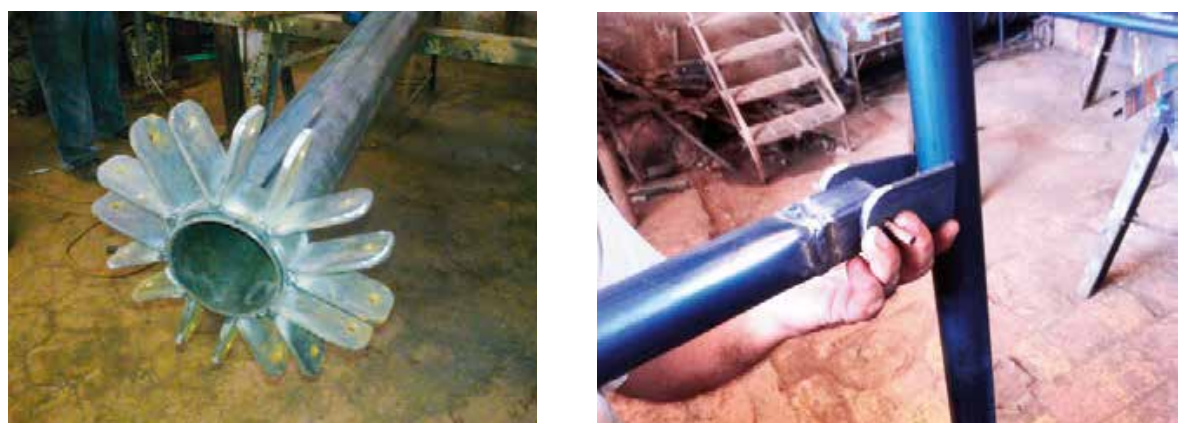

(4) (4) (1) Figuras 10 a 13. El proceso de manufactura del prototipo se facilitó por la utilización del acero
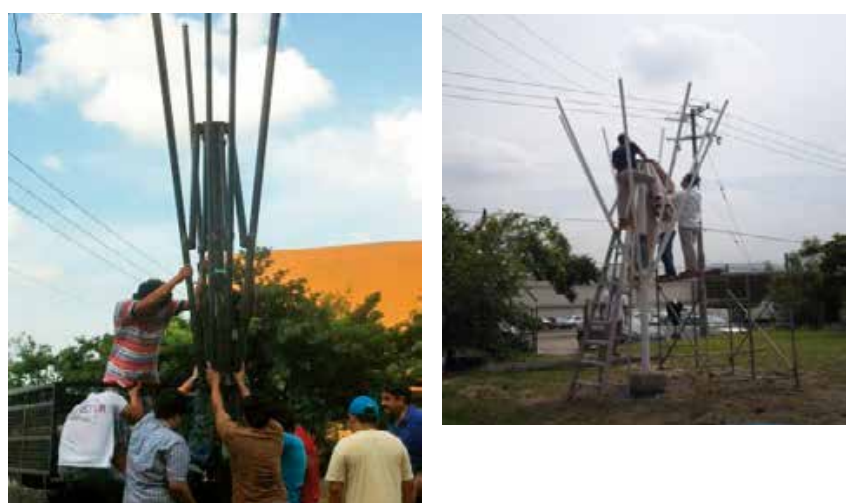

Fuente: Morales (2012; 2016, fig. 21)
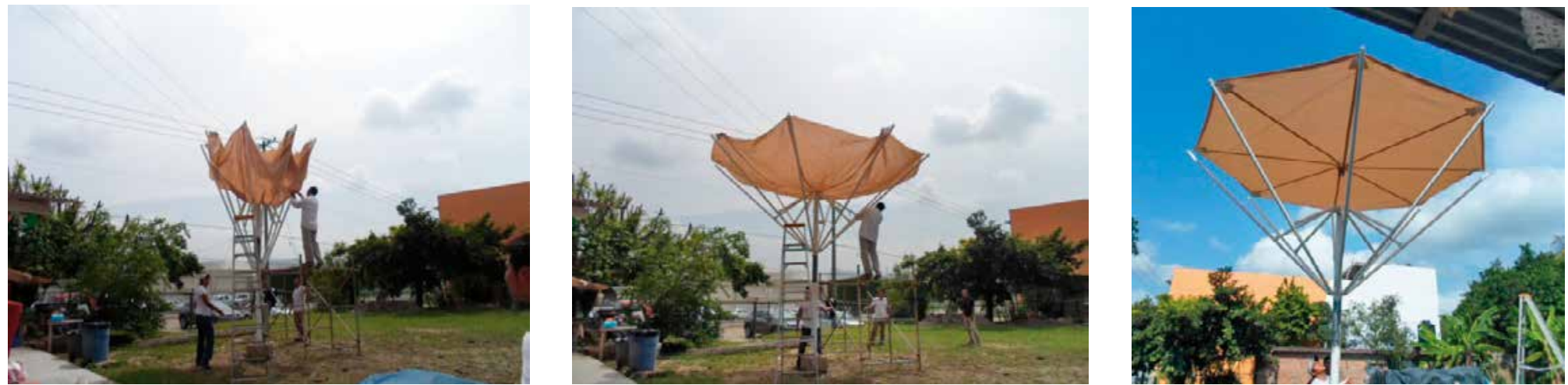

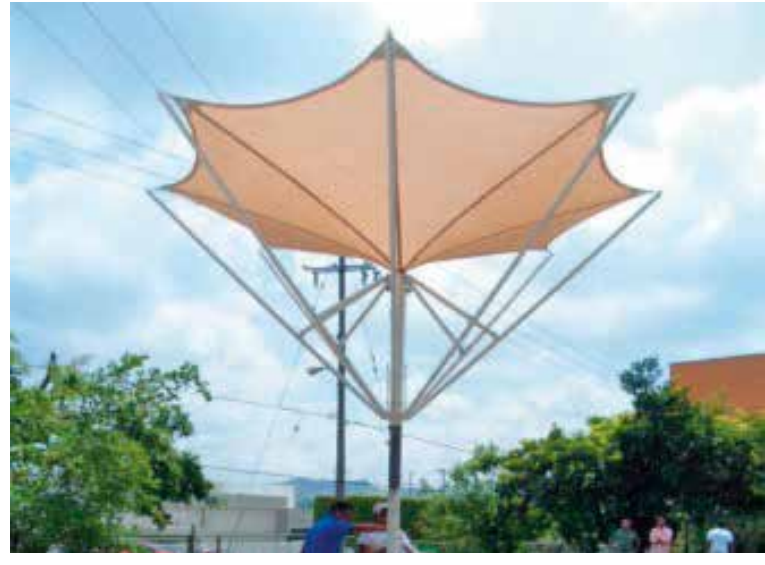

para hacer esto se efectuaron varias soldaduras en el detalle del poste en donde se colocaron los componentes que se articularon a los brazos, que posteriormente dieron la facilidad de plegarse a dichos miembros de la sombrilla. Después se fabricó la cumbrera, compuesta de varias piezas de placas de $1 / 4^{\prime \prime}$, con conexiones múltiples que ayudaron a rigidizar el sistema principal. Siguiendo con dicha construcción, se realiza un primer montaje para verificar la rigidez del poste en el dado de concreto; este dado se recuperó de la cimentación de 1,20 m de altura por $0,40 \mathrm{~m}$ de ancho del proyecto anterior, el cual está sujeto a una placa metálica de 1/2" de espesor que sirve de base para el poste; la cimentación es de $0,80 \times 0,80 \mathrm{~m}$, con un peralte de penetración de $15 \mathrm{~cm}$ para evitar el efecto del volteo por cargas horizontales. Se colocaron refuerzos de cartabón a los lados del poste para el efecto de pandeo por la presión del viento; asimismo, en la parte inferior se colocó un malacate al igual que en la cumbrera del poste (Figuras 34 a 41).
(A) (A) Figuras 14 a 17. Proceso constructivo del prototipo de paraguas plegable, este se desarrolló en la Facultad de Arquitectura de la UV.

Fuente: Morales (2012; 2016, fig. 22).

\begin{tabular}{|c|c|c|c|c|}
\hline \multicolumn{5}{|c|}{ Barras } \\
\hline & $\begin{array}{c}\text { Modelo } \\
\text { experimental: } \\
8,5 \text { metros }\end{array}$ & $\begin{array}{c}\text { Proyecto final: } \\
15,5 \text { metros }\end{array}$ & $\begin{array}{l}\text { Ratio 1: } \\
\text { modelo }\end{array}$ & $\begin{array}{l}\text { Ratio 2: } \\
\text { proyecto }\end{array}$ \\
\hline 2 & Ø110.5_A36 & Ø152.5_A36 & 1,27 & 1,05 \\
\hline 6 & Ø90.4_A36 & Ø75.4_A36 & 1,04 & ,95 \\
\hline 8 & Ø90.4_A36 & Ø75.4_A36 & 1,03 &, 97 \\
\hline 10 & Ø90.4_A36 & Ø75.4_A36 & 0,59 & 0,39 \\
\hline 11 & Ø90.4_A36 & Ø75.4_A36 & 0,65 & 0,58 \\
\hline 12 & Ø90.4_A36 & Ø75.4_A36 & 1,01 & ,93 \\
\hline 15 & Ø90·4_A36 & Ø75.4_A36 & 0,59 & 0,45 \\
\hline 16 & Ø90.4_A36 & Ø75.4_A36 & 1,05 & ,99 \\
\hline 22 & Ø90·4_A36 & Ø75.4_A36 & 0,68 & 0,52 \\
\hline 23 & Ø90·4_A36 & Ø75.4_A36 & 0,5 & 0,47 \\
\hline 25 & Ø90.4_A36 & Ø75.4_A36 & 0,62 & 0,39 \\
\hline
\end{tabular}

(A) Tabla 2. Resultado de resistencia de los miembros rígidos del sistema plegable de los dos proyectos

Fuente: Morales (2013)

\begin{tabular}{|c|c|c|c|c|}
\hline \multicolumn{5}{|c|}{ Tracción máxima en la membrana } \\
\hline Barra & Nudos & $\mathrm{T} /$ metro & $\mathrm{kg} / 5 \mathrm{~cm}$ & Ratio \\
\hline 56 & $120-135$ & 1,07 & 73,5 & 0,90 \\
\hline \multicolumn{5}{|c|}{ Tracción en los cables de relinga } \\
\hline Cable & $\mathrm{T}$ & Ratio & \multicolumn{2}{|c|}{ Barra } \\
\hline 1 & 1.250 & 0,10 & \multicolumn{2}{|c|}{$2,3(18 \mathrm{~mm})$ Galv } \\
\hline 2 & 1.357 & 0,095 & \multicolumn{2}{|c|}{ 1,4 (18 mm) Galv } \\
\hline 3 & 1.193 & 0,15 & \multicolumn{2}{|c|}{$5,6,7,8(18 \mathrm{~mm})$ Galv } \\
\hline
\end{tabular}

(A) Tabla 3. Resultado de resistencia de la membrana, relingas y acostillamientos Fuente: Morales (2013). 
$\gg$ Figuras 18 y 19 . Se desarrollaron los detalles constructivos de unión móvil del desplegado del sistema flexible, esta pieza es sumamente importante para el movimiento del paraguas, así como para la estabilidad de sus miembros, esta ayuda estabilizar la estructura en general

Fuente: Morales (2013)

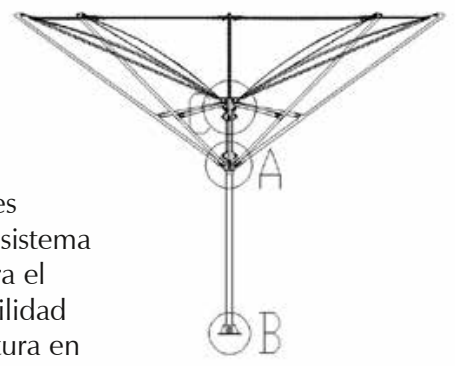

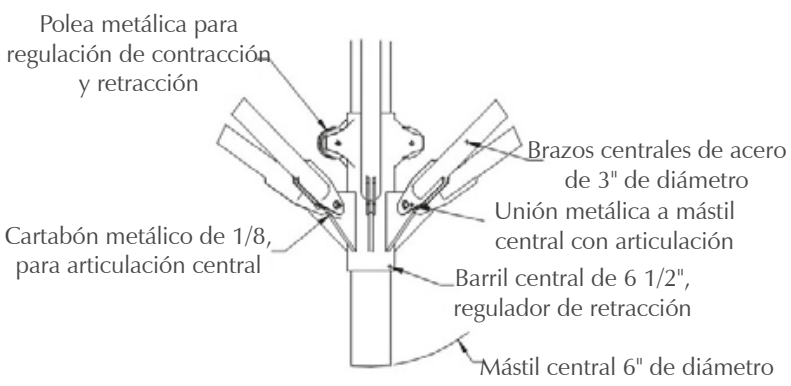

Detalle A $\gg \otimes$ Figuras 20 y 21 . Las uniones articuladas dentro de los miembros secundarios de la estructura contienen la forma final del paraguas, el detalle del soporte proporciona la rigidez adecuada del sistema

Fuente: Morales (2013)

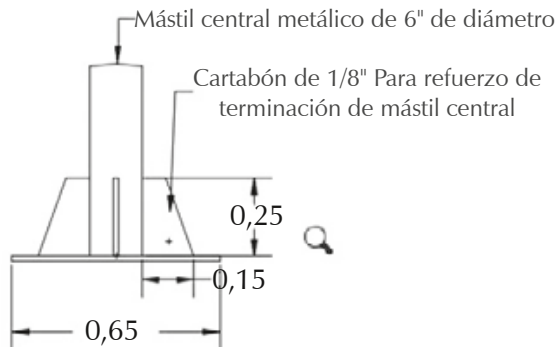

Detalle B

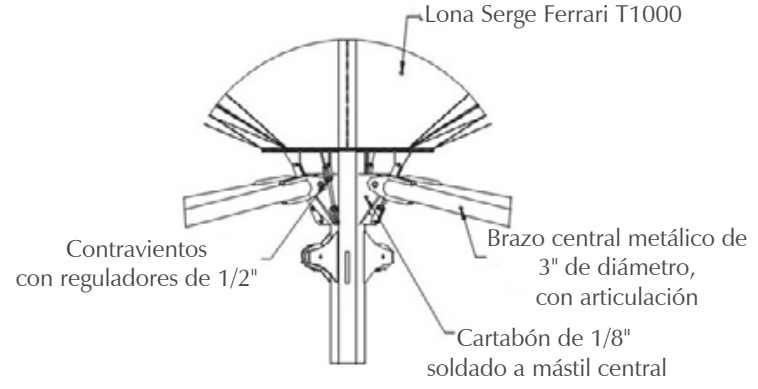

Detalle C
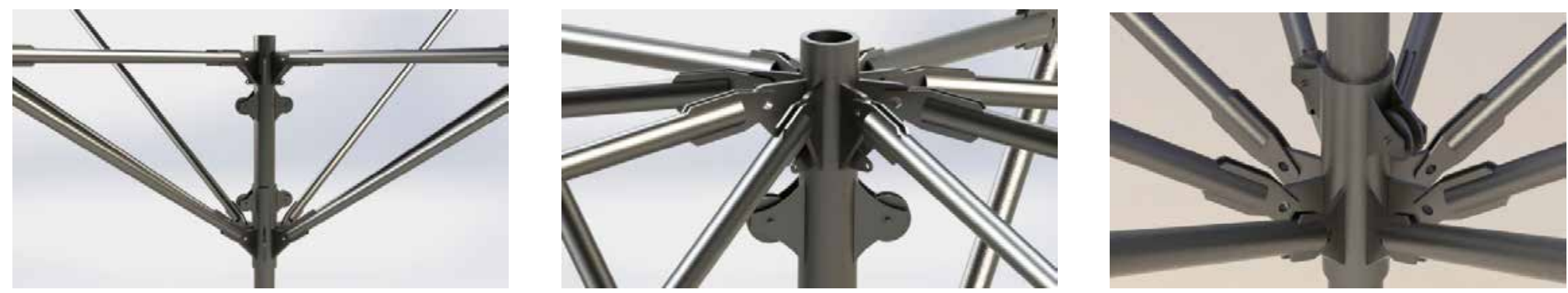

(A) (A) Figuras 22 a 24. Las uniones articuladas que dan movimiento al sistema plegable del paraguas son las que detonan la forma final del sistema transformable y manifiestan la funcionalidad de la estructura en una etapa teórica del proyecto que permite que su construcción sea viable Fuente: Morales (2013).

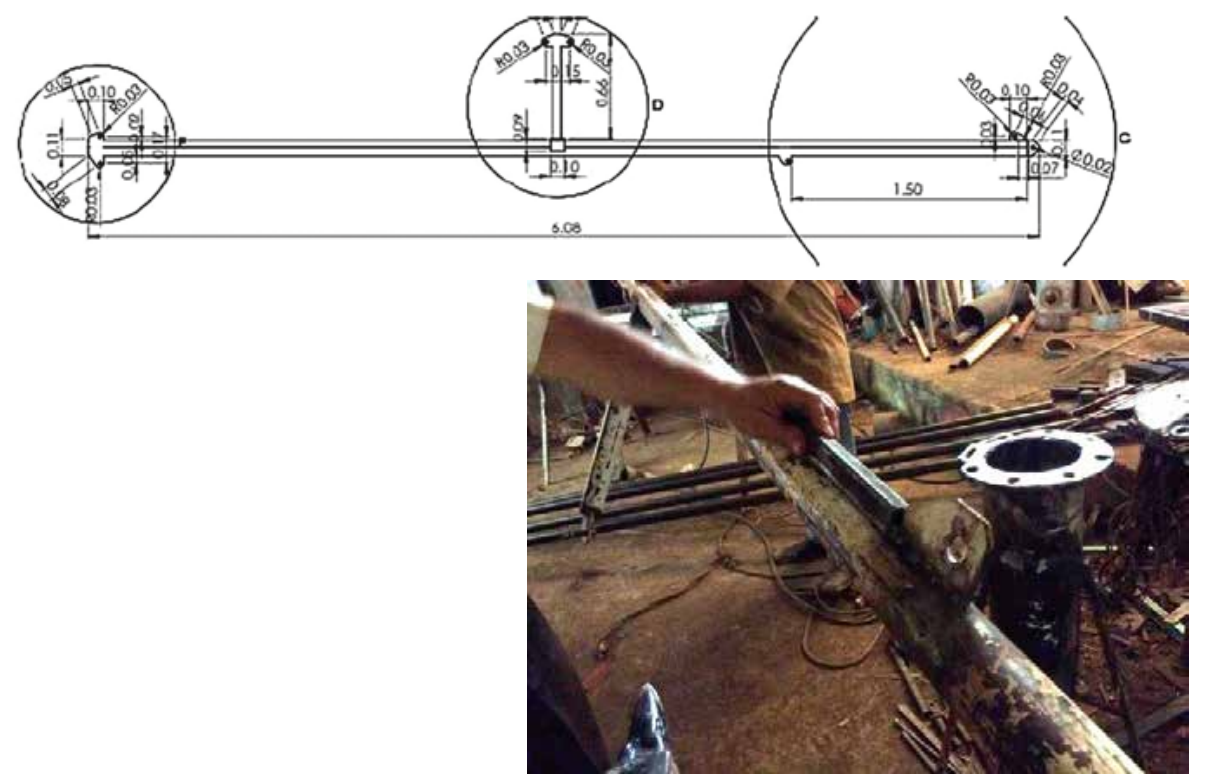

(A) Figuras 25 a 27. El brazo de $\geqslant$ despliegue del paraguas $\nabla$ constituyó una corrección muy importante para el proyecto final, ya que con esta configuración de poste cable que desarrollamos podíamos alcanzar dimensiones mayores a las obtenidas, en este caso solo 15,5 metros, pero en el análisis estructural hasta 50 metros de diámetro

Fuente: Morales (2013).

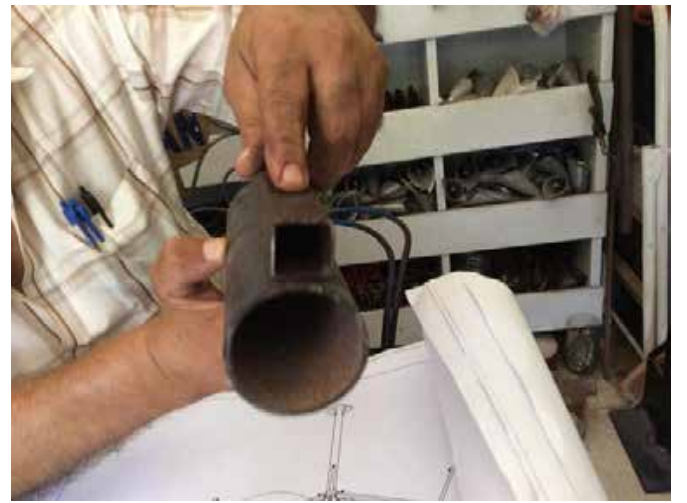

82
Después se manufacturaron los brazos de la sombrilla, los cuales serían postes cables que ayudarían a tener mayor inercia a los brazos para evitar un esfuerzo mayor a los postes; los brazos del paraguas se forman con los postes viga hechos con un tubo de 3 " de diámetro y $5 \mathrm{~mm}$ de espesor; se realizó un refuerzo de PTR de $2 \times 2$ " en la parte inferior del poste para evitar algún pandeo y plastificación del material por el esfuerzo que se genera a la hora de plegarse o desplegarse la estructura (Figuras 42 y 43 ). En esta fase se colocaron los cables de $12 \mathrm{~mm}$ de espesor en las uniones de sujección de los postes para conformar la figura final del poste cable; en las uniones se instalaron reguladores de $1 / 2$ " para tensar el cable, y grilles de 3/8" para sujetar dichos reguladores.

En la fabricación de la membrana se realizaron uniones metálicas con placas de 1/4" de espesor y con tornillos de $12 \mathrm{~mm}$ de diámetro, dichas uniones fueron colocadas en las puntas de la membrana, estas se reforzaron con una lona de plástico para evitar el desgarramiento de la membrana que en este caso fue malla sombra; dentro de las fronteras de la membrana se colocaron cables de $14 \mathrm{~mm}$ de diámetro que sirvieron como relingas y se sujetaron a reguladores de $3 / 8$ " soldados en las 

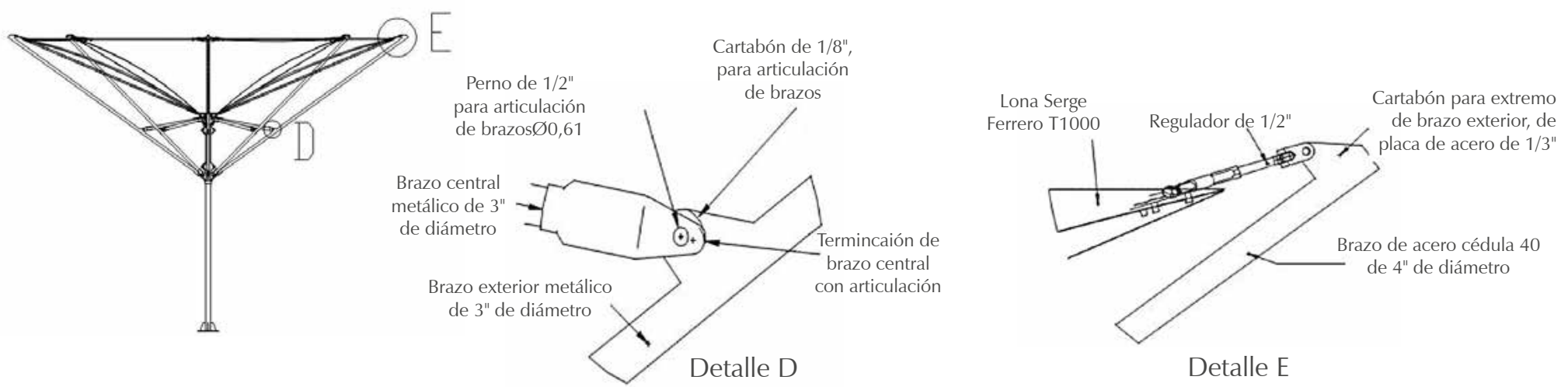

(A) (4) (A) Figuras 28 a 30. Los detalles de las uniones del paraguas plegable ayudarán posteriormente al proceso de manufacturación; en este caso, los detalles de articulación del paraguas que sostendrá los postes vigas y los detalles de uniones de la membrana a dichos postes que ayudarán a tensar la membrana

Fuente: Morales (2013).

uniones de las conexiones; se colocó una conexión octagonal con tornillos de $10 \mathrm{~mm}$ con uniones articuladas que se sujetaron al poste central para articular la membrana para darle flexibilidad a la superficie (Figuras 44 a 48).

Posteriormente se preparó la estructura para el montaje de los miembros de esta al poste principal; se empezó con los brazos de anclaje del desplegado de la sombrilla, unidos a la cumbrera metálica del poste principal (Figuras 49 a la 52), ya colocados los ocho brazos se conectaron los postes viga, sujetados por medio de un tornillo y una tuerca de 1" de espesor, con ello se articula el poste para plegarse y llegar a una posición abierta a fin de tensar la membrana del paraguas. Una de las dificultades del proyecto fue este primer ensamble ya que la colocación de los postes cables era crítica y debían tener una exactitud de milímetros en cada brazo articulado; cada colocación se llevó aproximadamente de 15 a 20 minutos, por lo cual su supervisión fue esencial para que el armado de este paraguas fuese unido con éxito (Figuras 53 a 63), se utilizó la ayuda de dos andamios de $3 \mathrm{~m}$ de alto para colocar cada miembro y así obtener la estructura ya ensamblada.

Luego se ejecutó una prueba de movilidad sin la membrana, esto para probar que los malacates se hubieran puesto en la cumbrera y en el pedestal del nodo plegable; la demostración ayudó a probar que los brazos resistirían el esfuerzo del movimiento y verificar la movilidad del desplegado, esta primera prueba también sirvió para examinar si el movimiento no producía una sobretensión en los miembros estructurales (Figuras 64 a 66); la prueba fue un éxito y no hubo ninguna deformación en la estructura, esta se mantuvo en buen estado en todo el sistema estructural y no causó ninguna plastificación en las placas de unión de las conexiones articuladas.

En consecuencia se pasó a poner la membrana en los ocho puntos de los brazos del paraguas, para lo cual se ubicaron dos andamios a una altura de 9 metros cada uno, estos ayudaron a que el personal de trabajo hiciera el montaje de los ocho grilletes y ocho reguladores de $1 / 2^{\prime \prime}$; en cada conexión de la frontera del brazo del paraguas se colocaron las uniones metáli-

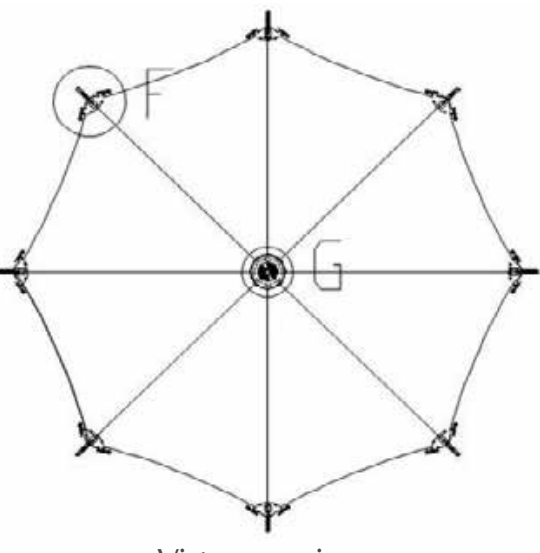

Vista superior

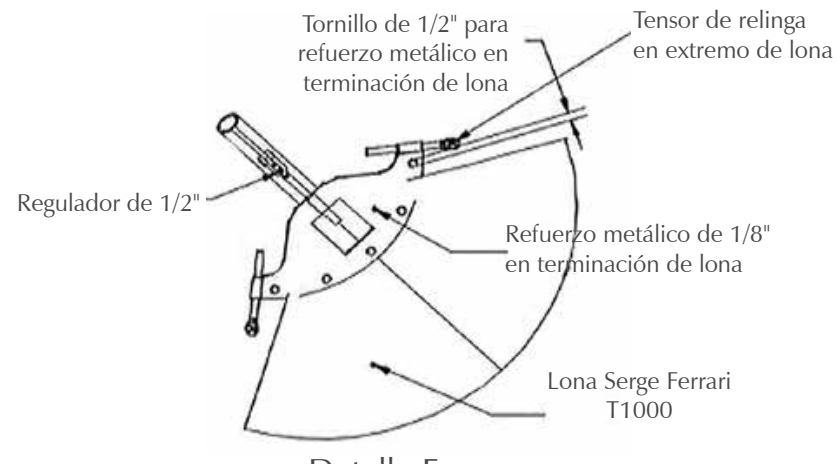

Detalle F

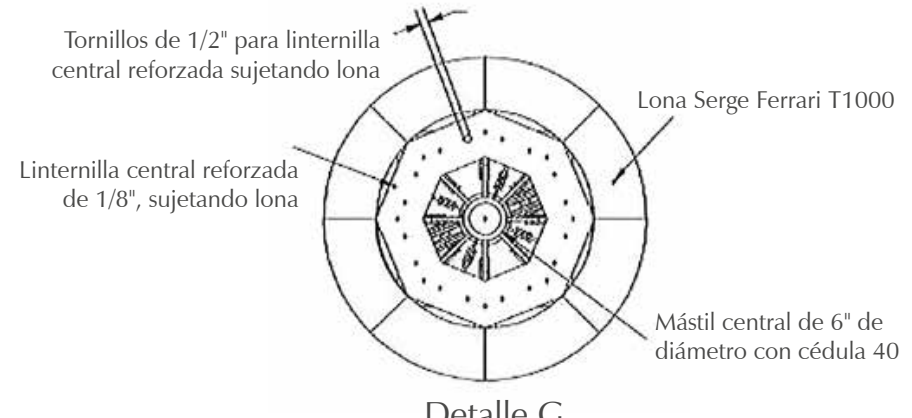

(A) Figuras 31 a 33. Los detalles constructivos

(A) de las uniones de la membrana a la estructura facilitan

(A) la fabricación y el estandarizado de las conexiones para su

armado en el sitio, lo que aumenta la velocidad de construcción de la sombrilla plegable

Fuente: Morales (2013).

cas reguladas con la membrana; las religas y los acostillaientos ya estaban pretensados, esto hizo que el desplegado fuese más fácil en un segundo momento; al mismo tiempo, se colocó la conexión central de la membrana a los cuatro reguladores del poste central (Figuras 67 a 72) (Morales, 2012, 2013, 2014). 
(7) Figuras 34 a 41. La fabricación del poste central, con su nodo deslizante y su cumbrera, facilitó que el proceso de armado posterior fuese más rápido; en esta fase su montaje fue relativamente veloz gracias a que se reutilizó la zapata anterior del proyecto experimental

Fuente: Morales (2013).
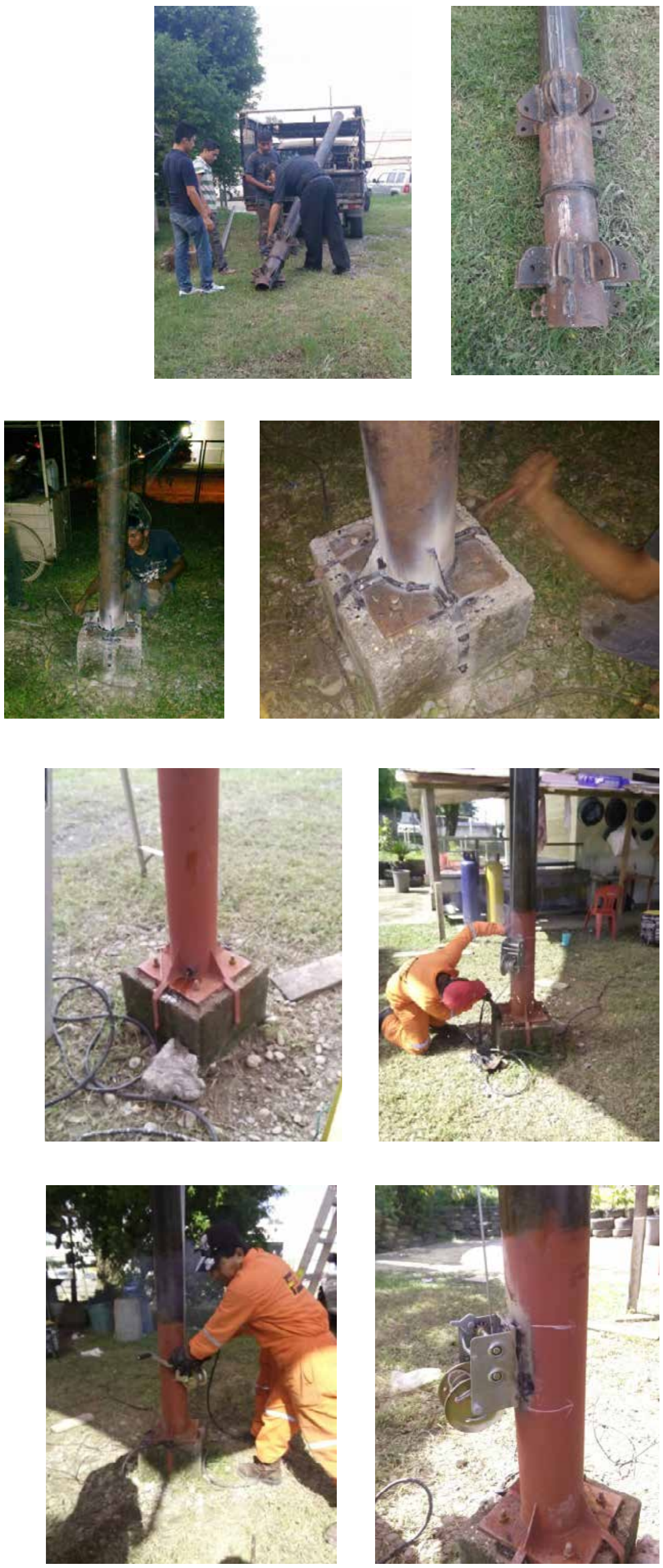

(7) Figuras 42 y 43. La fabricación del poste-viga se realizó bajo la configuración del detalle constructivo y el análisis estructural previo, el cual ayudó a generar una crítica conceptual estructural de triangular el esfuerzo por medio de un cable y un poste central, alejando su centro de masa y ganando mayor inercia

Fuente: Morales (2013)
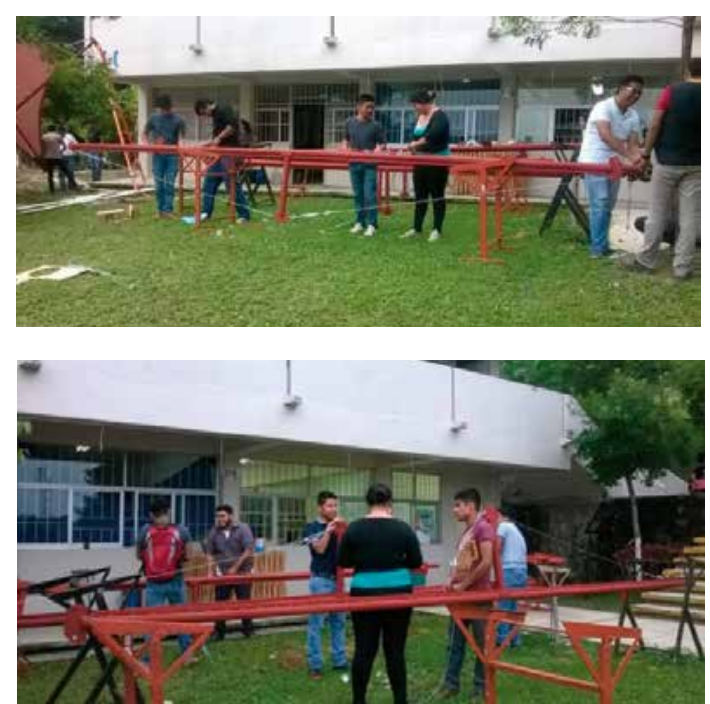

\section{Proceso de despliegue del paraguas}

A continuación se realizó la prueba de desplegado con la membrana en dos fases, con ello se pretendía comprobar si el poste principal soportaría la fatiga de desplazamiento de los brazos plegables; la primera prueba fue para verificar si las uniones de la membrana estaban conectadas correctamente a las uniones del paraguas (Figuras 73 a 78). En la primera fase se realizó el desplegado de los malacates con mucha lentitud para ver si los reguladores estaban correctamente fijados y abiertos, esto para que el despliegue funcionara adecuadamente y la membrana se tensara y así se generara la forma final; se observó que hubo errores en los reguladores y estos no se abrieron totalmente, por ende, no se pudo abrir toda la membrana, esto ocasionó que la membrana se abultara y no se generara la forma.

En la segunda fase del despliegue, que se realizó ya con la membrana, se abrieron completamente los reguladores para que esta pudiera abrirse de forma adecuada (Figuras 79 a 87), las uniones tensaron la malla sombra generada en el programa de simulación de WinTess, y se formó la curva que da rigidez a los acostillamientos interiores para estabilizar la estructura correctamente, los brazos del paraguas también quedaron tensados gracias a los cables que forman la figura triangular de los postes cables (Morales, 2012, 2013, 2014, 2015).

\section{Discusión}

En la actualidad, el estudio de sistemas transformables y su construcción en la arquitectura se basa principalmente en la experimentación. Esto se puede apreciar en el caso de la modelación para verificar la movilidad, la cual se basó en la modelación y verificación por medio de software, el cual fue una gran ayuda para realizar el proyecto final; esto da como resultado un sistema estructural 
(1) Figuras 44 a 48. La fabricación de las uniones del paraguas transformable ayudó a que se estandarizaran las conexiones de la membrana, esto gracias al previo detalle de los planos constructivos y a la experiencia de los modelos anteriores

Fuente: Morales (2013).
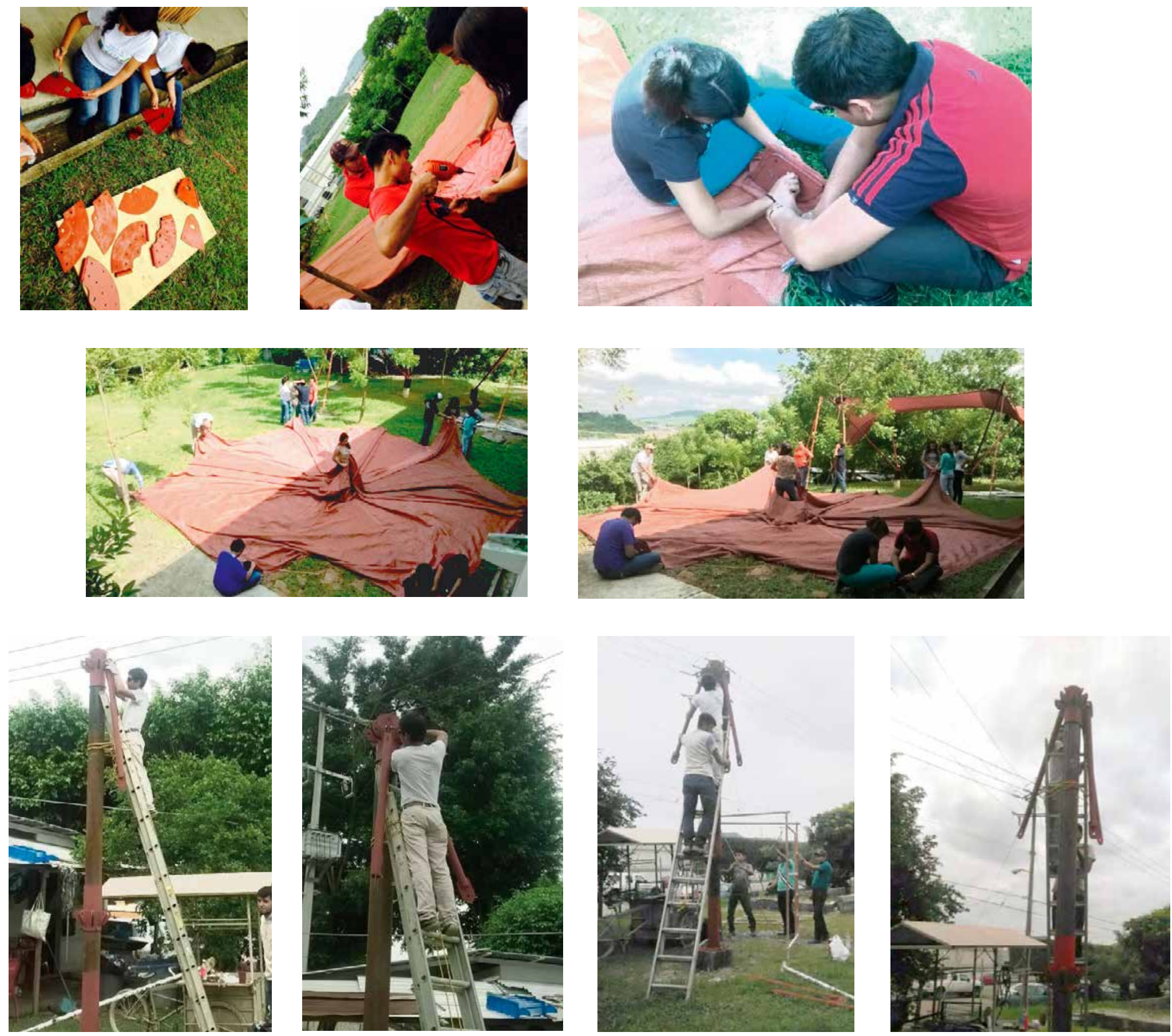

configurable a su entorno, con la capacidad de transformar su forma dentro del espacio arquitectónico. Su principio de diseño versó sobre cómo desarrollar un sistema plegable con conexiones articuladas, el cual lograra enlazar mecanismos móviles y resistentes.

Esta investigación se justificó en la línea de tiempo y las tecnologías actuales. Este estudio metodológico mejora el sistema que se empleó en el proyecto, pero con una tecnología más adecuada a la región; vale la pena mencionar que son pocas las instituciones que generan trabajos de praxis que lleguen a la materialización de un sistema transformable, para mencionar uno de ellos: el doctor Juan Gerardo Salinas, encargado del laboratorio de estructuras de la Universidad Nacional Autónoma de México, y el doctor José Ignacio Llorens Durán, son de los pocos académicos que incluyen a los estudiantes en la rea- lización de modelos de cubiertas ligeras; esta inclusión de alumnos al proyecto crea una gama nueva de estudiantes con mayor conocimiento en la construcción de este tipo de estructuras.

Luego de la investigación se generaron hipótesis que ayudaron a realizar un prototipo final de sistema transformable, esto fue un factor muy significativo para una aproximación conceptual, porque sus aportes teórico-prácticos sirvieron para realizar la transición geométrica del proyecto, esto ayudó a construir un sistema transformable, con el desarrollo de diferentes hipótesis de proceso modelístico, se compararon con modelos aproximados de construcción, lo cual sirvió para la estructura final.

Todo esto deja diferentes líneas de investigación paralelas para abordar y generar más conocimiento práctico-teórico, pero en esta investigación solo se desarrolla la simulación estructural para
(A) Figuras 49 a 52. Primero se colocaron los postes centrales de la cumbrera superior, estos ayudan a sostener y plegar a los brazos principales que tensan la membrana del paraguas

Fuente: Morales (2013). 

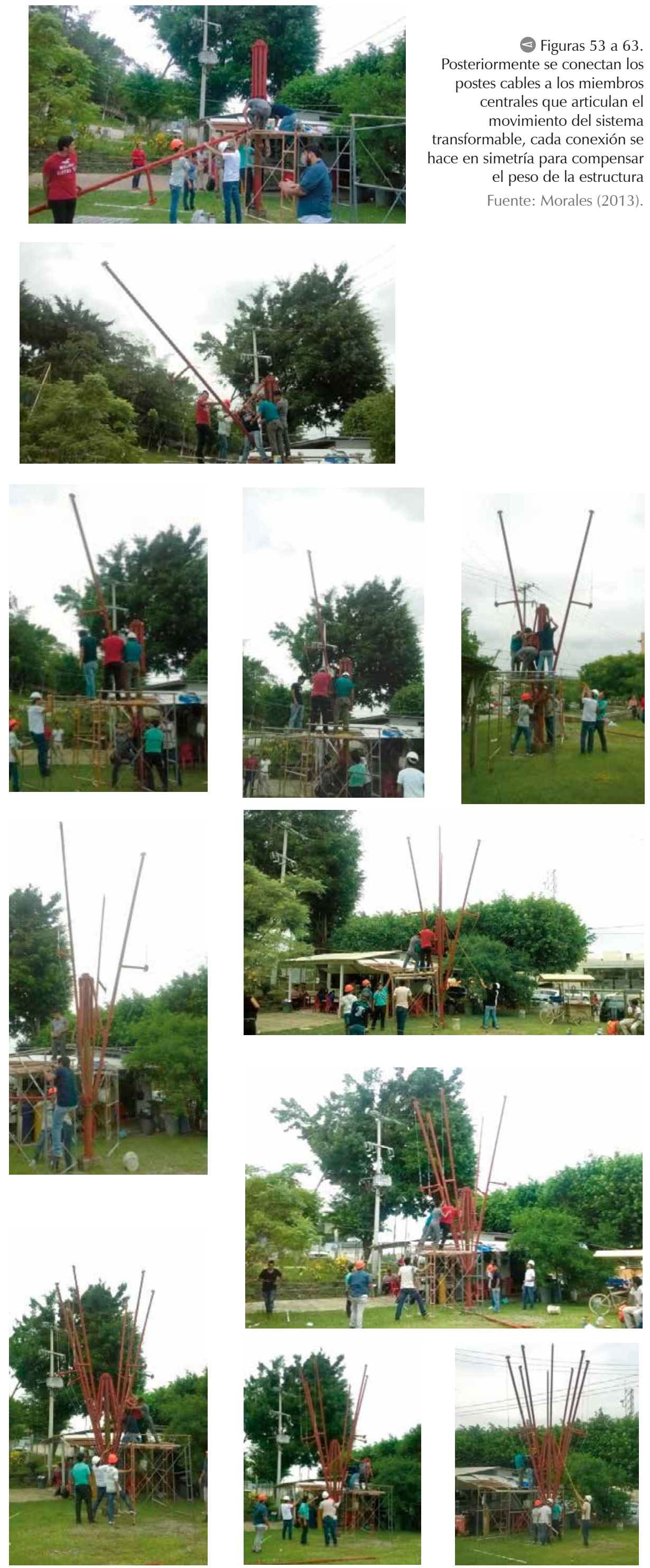

Posteriormente se conectan los postes cables a los miembros centrales que articulan el movimiento del sistema transformable, cada conexión se hace en simetría para compensar el peso de la estructura Fuente: Morales (2013).
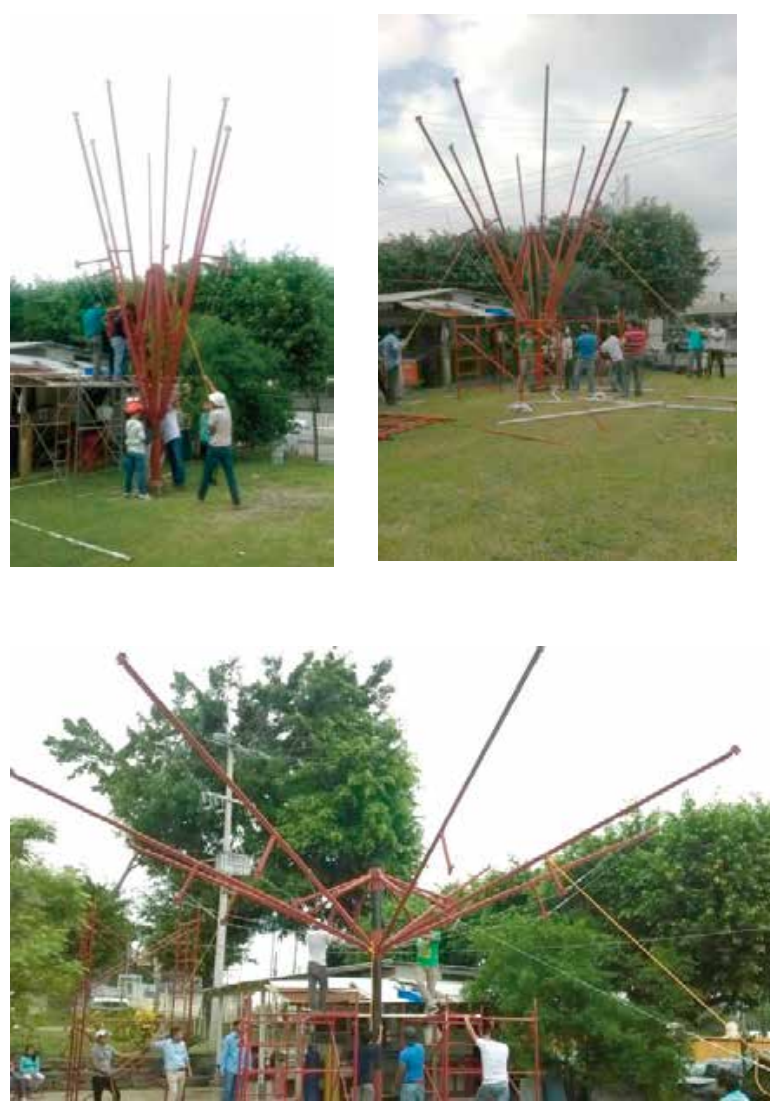

realizar una comparativa del anterior prototipo, ajustando el mejoramiento optimo del diseño, ya que, dependiendo del tipo de uso que se le brinde al espacio arquitectónico se colocarán la solicitaciones de carga de servicio a la estructura que, en este caso, se maneja para uso institucional, aunque la estructura puede cumplir otras funciones.

En cuanto a las aplicaciones arquitectónicas de esta investigación, que se reflejaron en la realización de la estructura, se encontraron opciones constructivas debido la carencia de herramientas especiales y costo del material, pero el elaborar la estructura ayudó a desarrollar preparaciones desconocidas en la práctica, una de ellas fue el proceso de montaje manual, sin herramientas especializadas y con andamios, lo cual generó premisas y alternativas para construir las conexiones finales con mucha más sencillez y menos complejas; también se consideró la tenso-estructura desde un principio, para saber de antemano las tensiones reales que iban a interactuar en el diseño de esta estructura plegable, así como para verificar otras normas y materiales que pudieran mejorar el proceso de la construcción. Por último, este modelo deja claro que la aplicación de este tipo de sistemas plegables puede ser una alternativa constructiva para la región norte de Veracruz para espacios urbanos y arquitectónicos, ya que son relativamente fáciles de montar en sitio. 
(1) Figuras 67 a 72. Posteriormente se colocó la membrana pretensada al paraguas, con ayuda de dos andamios armados de $9 \mathrm{~m}$, en cada conexión se colocó un regulador y un grillete de $1 / 2^{\prime \prime}$, que sirve de articulación flexible a la hora del despliegue Fuente: Morales (2013).
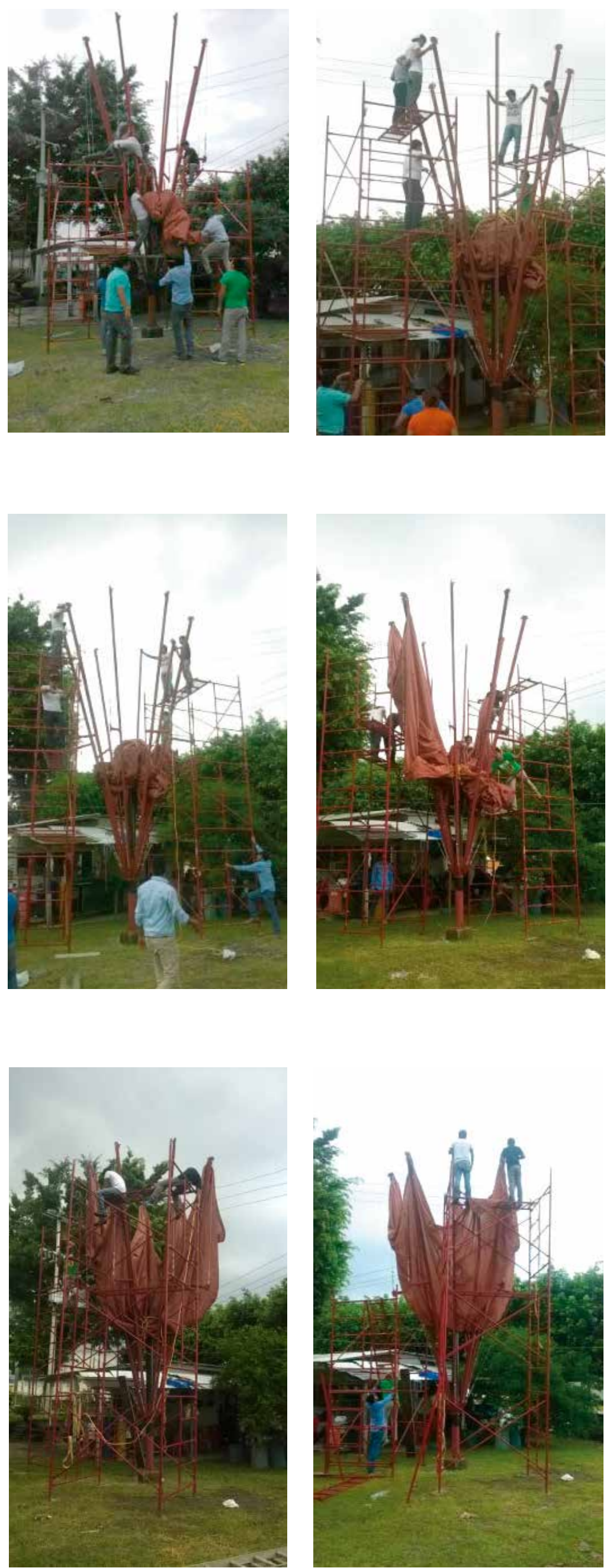

(7) Figuras 73 a 78. Se realizó el primer despliegue del paraguas plegable con membrana; este primer intento falló porque los

reguladores estaban semiabiertos y esto impidió que la membrana se tensara completamente

Fuente: Morales (2013).
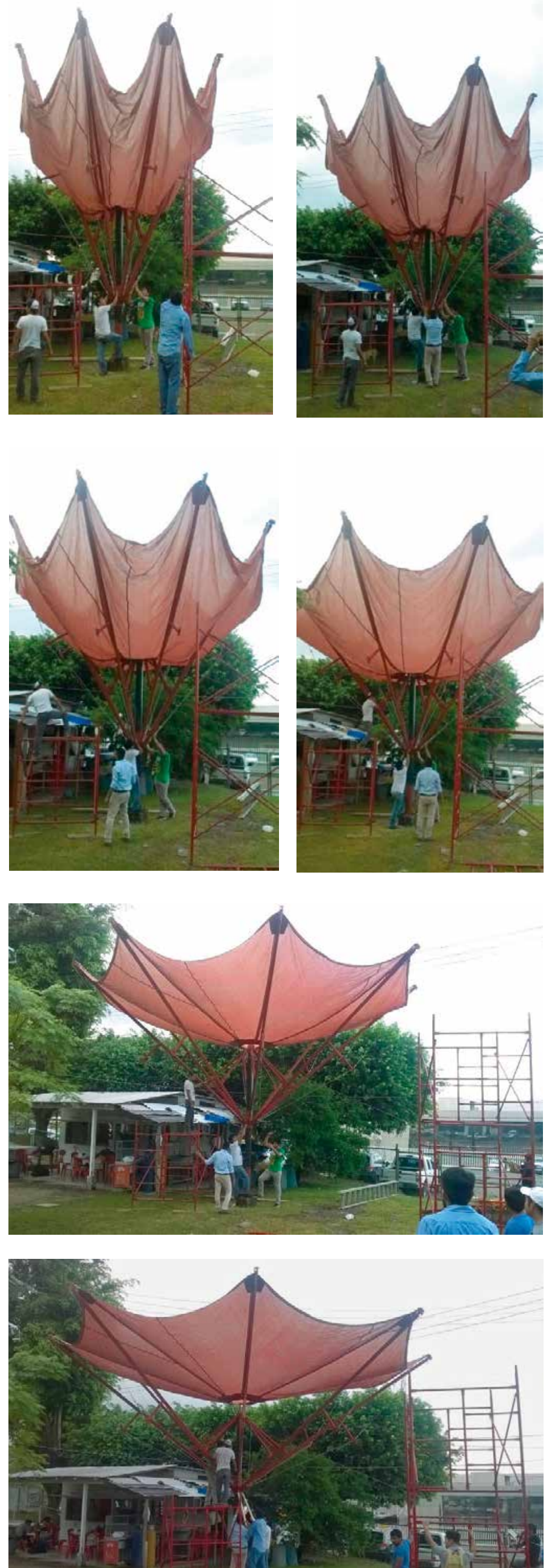

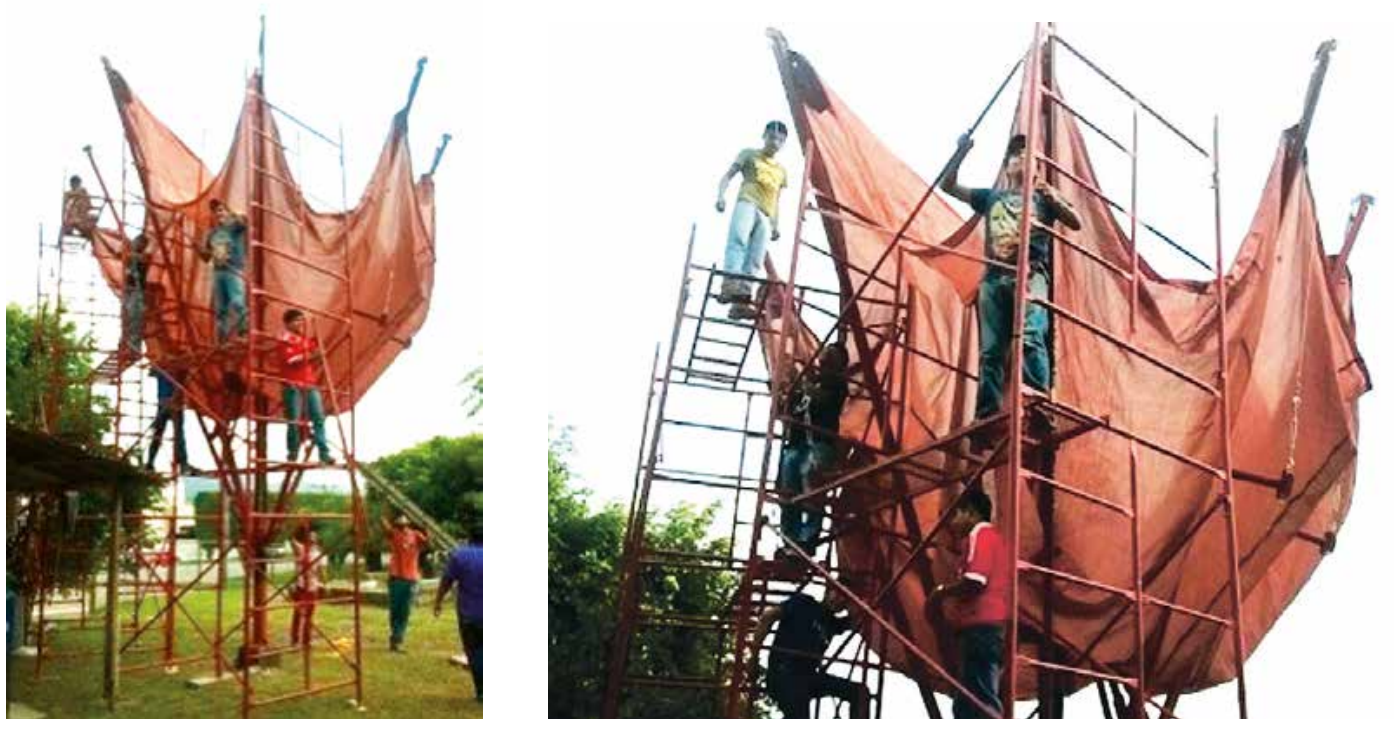

(4) Figuras 79 a 87. Se realizó el segundo despliegue del paraguas plegable con membrana; en este segundo intento los reguladores estaban abiertos y esto ayudó a que la membrana se tensara completamente y el proyecto fuera un éxito

Fuente: Morales (2013).
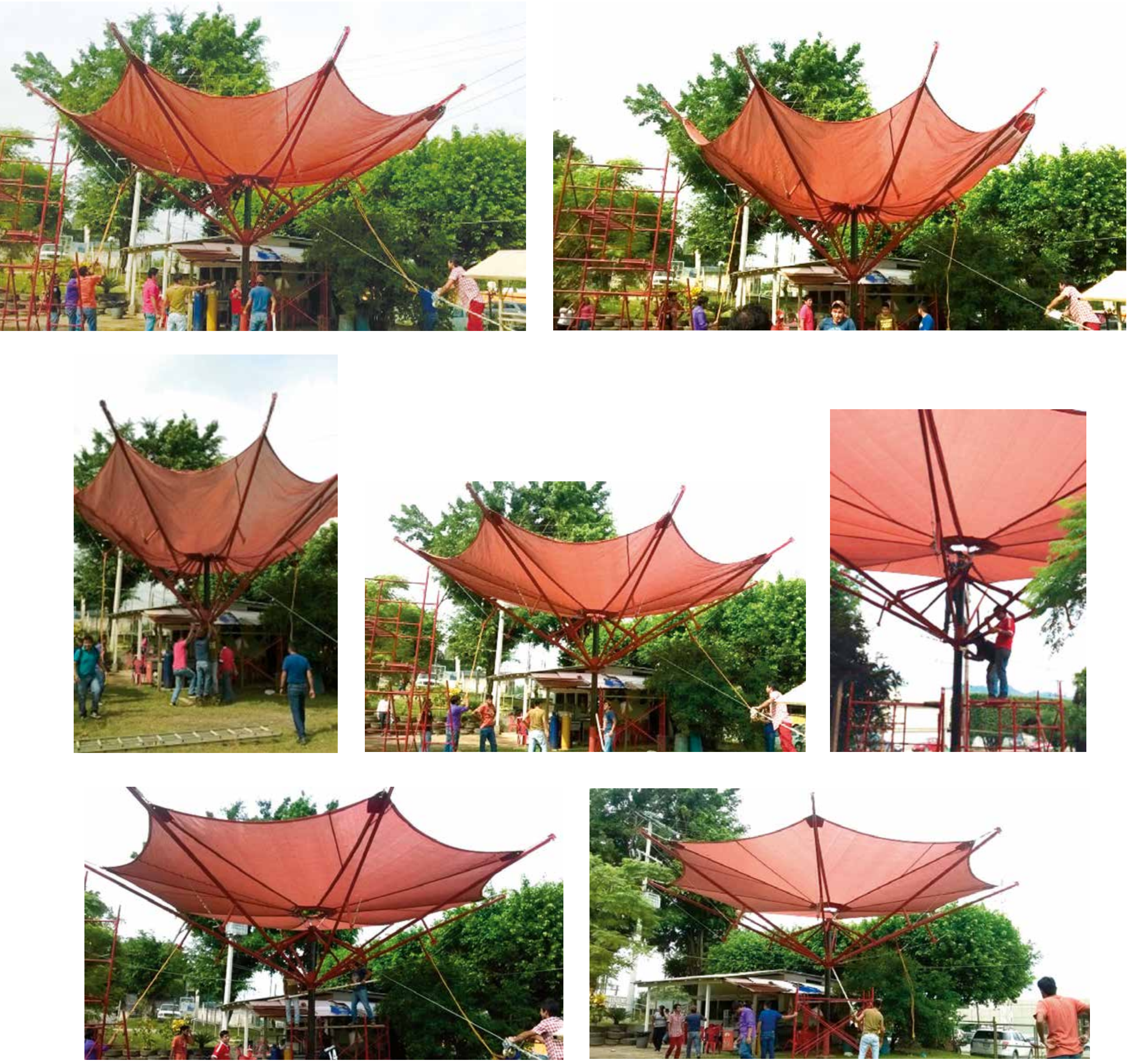


\section{Conclusiones}

Este proyecto de investigación se basó desde el principio en la metodología de diseño del arquitecto Emilio Pérez Piñero y el doctor Felix Escrig, ya que ellos desarrollaron geometrías estandarizadas que ayudaron a generar sistemas transformables más fáciles de manufacturar para construir espacios arquitectónicos más eficientes y rápidos de montar en sitio.

A fin de desarrollar la geometrización de modelos transformables se utilizó la simulación de los software para realizar análisis de segundo orden, ya que este tipo de estructuras puede ubicarse dentro del campo de las estructuras transformables, dado que requieren de mecanismos en las uniones articuladas para materializar su movilidad y pueden retornar a su estado inicial. Finalmente, con los parámetros necesarios se tendrá un planteamiento para proponer y definir aproximaciones o resultados de los estudios previos bajo el análisis comparativo de prototipos, con el objetivo de demostrar la viabilidad de la propuesta y, a la vez, experimentar con diferentes materiales con modelos a escala, cuya finalidad es seleccionar el que se utilizará. Para ello, se realizó una comparación entre el prototipo a escala real construido con un método puramente artesanal, pero analizado con el rigor científico que sustenta su resistencia y equilibrio en el espacio y, con ello, se cotejan aspectos tales como los constructivos y sus reacciones, una vez que la cubierta está completamente desplegada.

Los alcances de estas comparaciones ayudaron a adquirir experiencia y conocimiento en la manufactura de los miembros estructurales del modelo; de igual manera para la aplicación de sistemas como las vigas tensadas que se colocaron debajo del brazo del paraguas retráctil. Esta aplicación ayudó en gran medida a bajar el peso del sistema plegable, y a que se pudiera realizar el plegado de la estructura con un malacate, ya que dicho modelo se realiza en acero. También la práctica ayudó a resolver cómo incluir este tipo de proyectos en el espacio arquitectónico. Por último, el proyecto aportó a la generación de nuevo conocimiento para los estudiantes de licenciatura y posgrado que serán los profesionales que propondrán dichos sistemas en su vida profesional; asimismo, dicha investigación sirvió para generar una posterior vinculación con el ayuntamiento de la Ciudad de Poza Rica, el cual realizará un proyecto arquitectónico de tenso-estructuras y estructuras transformables en el parque Cuauhtémoc de dicha ciudad. Este proyecto construido servirá para incentivar a arquitectos y responsables de desarrollo urbano a fin de generar proyectos con este tipo de sistemas (Morales, 2009, 2012, 2016).

\section{Referencias}

Buckminster Fuller, R. (1963). Nine Chains to the Moon. Carbondale: Southern Illinois University Press.

Escrig Pallares, F. E. y Valcarel, J. P. (2012). Modular, ligero, transformable: un paseo por la arquitectura ligera móvil. Sevilla: Universidad de Sevilla.

Morales-Guzmán, C. C. (2009). Diseño de sistemas estructurales flexibles en el espacio arquitectónico. Ciudad de México: Universidad Nacional Autónoma de México, UNAM.

Morales-Guzmán, C. C. (2012a). Diseño de sistemas flexibles en el espacio Arquitectónico. Madrid: Editorial Academia Española.

Morales-Guzmán, C. C. (2012b). Diseño de una cubierta retráctil tensada. Actividad Posdoctoral. Barcelona, Universidad Politécnica de Catalunya

Morales-Guzmán, C. C. (2013). Informe técnico: sistemas estructurales retráctiles. Veracruz: Universidad Veracruzana.

Morales-Guzmán, C. C. (2013a). Mejoramiento del diseño de una cubierta plegable tensada. Actividad Posdoctoral. Barcelona, Universidad Politécnica de Catalunya.
Morales-Guzmán, C. C. (2013b). Prototipo: diseño de una cubierta retráctil tensada. Veracruz: Universidad Veracruzana.

Morales-Guzmán, C. C. (2013c). Prototipo de diseño de una cubierta retráctil tensada. Revista de Arquitectura, 15(1), 102-110. doi: http:// dx.doi.org/10.14718/RevArq.2013.15.1.11

Morales-Guzmán, C. C. (2014a). E.E. Diseño Arquitectónico: Detalles. Veracruz: Universidad Veracruzana.

Morales-Guzmán, C. C. (2014b). Construcción de un paraguas transformable tensado. Ponencia en el II Congreso Internacional de Ingeniera Civil, La Habana, Cuba.

Morales-Guzmán, C. C. (2015). Arquitectura e ingeniera transformable. Estancia Posdoctoral. Sevilla, Universidad de Sevilla.

Morales-Guzmán C. C. (2016). Construcción experimental de un sistema transformable tensado plegable. Revista de Arquitectura, 18(1), 98-110. doi: http://dx.doi. org/10.14718/RevArq.2016.18.1.9

Morales-Guzmán, C. C. y Rivera Torres, H. (2017). Experiencias y casos de estudio: construcción de una cubierta hiperbólica tensada para espacios tropicales. En Pesan- tez, G. y Flores, W. (comps.). Arquitectura: experiencias y propuestas para la ciudad (pp. 177-192). Guayaquil: Centro de Investigaciones y Desarrollo de Ecuador.

Reglamento de construcción del Distrito Federal (RCDF). Recuperado de: http://www.fimevic.df.gob.mx/documentos/transparencia/ reglamento_local/RCDF.pdf

Rodríguez Gonzales, N. (2005). Diseño de una estructura transformable por deformación de una malla plana en su aplicación a un refugio de rápido montaje. Barcelona: Universidad Politécnica de Catalunya. Recuperado de: https://upcommons.upc.edu/ handle/2117/93438

Sastre, R. WinTess (Versión 3.1) [Software computacional]. Barcelona: Escuela Técnica Superior de Arquitectura, Universidad Politécnica de Cataluña.

Segui, W. (2000). Diseño de estructuras de acero con LRFD. México: Thomson. Recuperado de: https://es.scribd.com/document/253987220/ Diseno-de-Estructuras-de-Acero-Con-Lrfd-Segui 


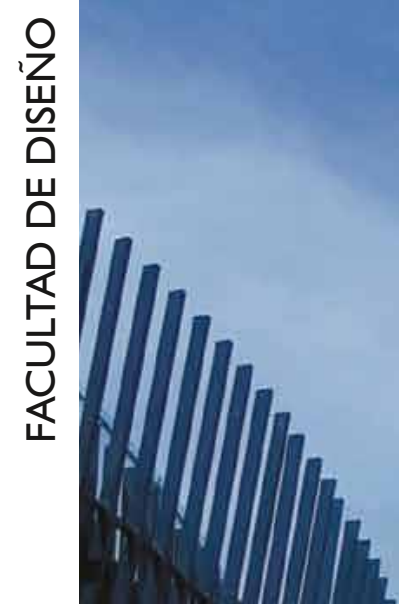

Vol.

\section{Nro. 1REVISTA DE ARQUITECTURA}
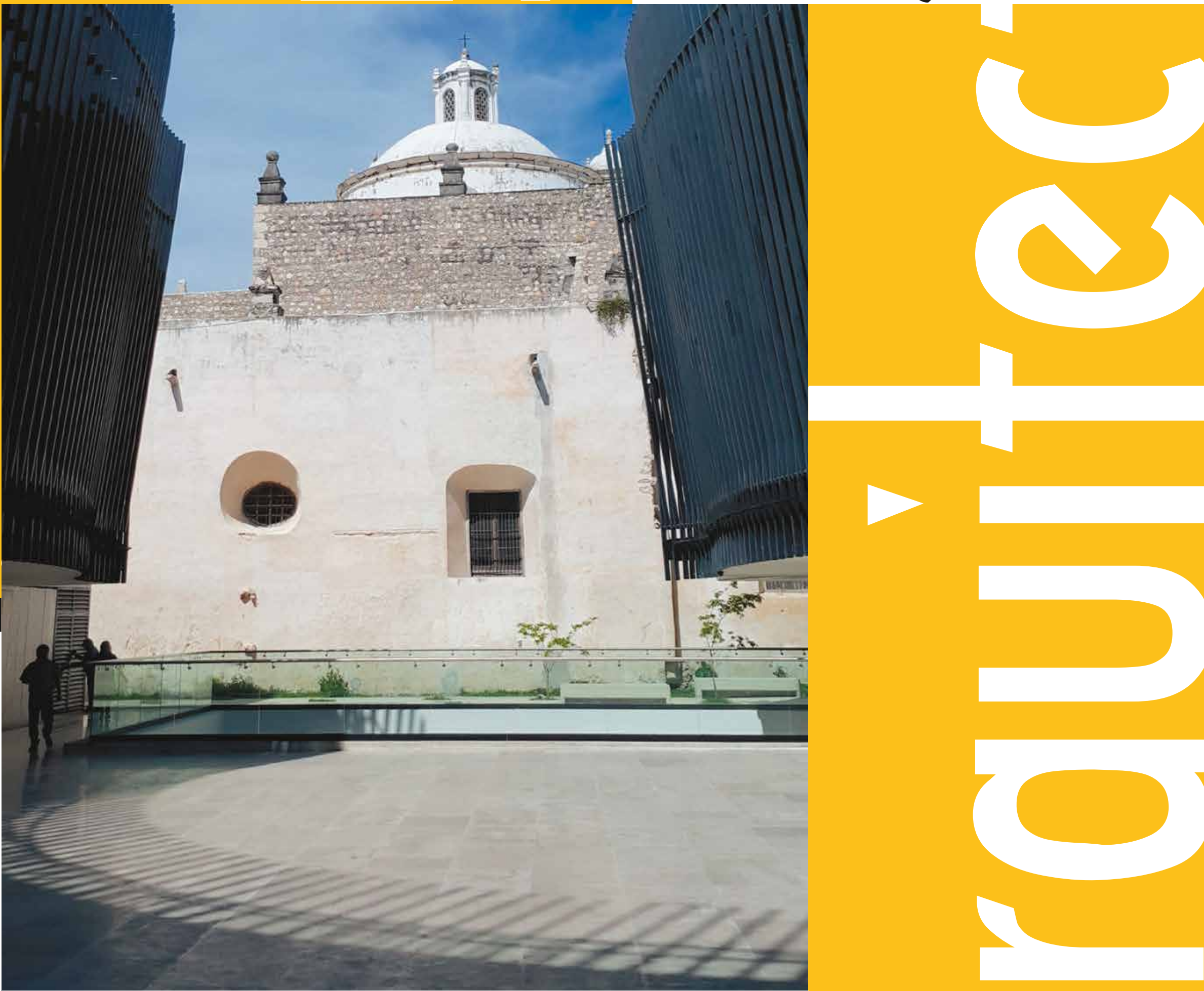
A) Portada: Palacio de la Música y Rectoria El J Júśs Tercera Orden. Mérida, Yucatán (México).

\section{() (1) $\Theta$}

A Orientación editorial

\section{Enfoque y alcance}

La Revista de Arquitectura (Bogotá) ( (ISSN 1657-0308 Impresa y E-ISSN 2357-626X en línea) es una publicación seriada de acceso abierto, arbitrada mediante revisión por pares (doble ciego) e indexada, en donde se publican resultados de investigación originales e inéditos.

Está dirigida a la comunidad académica y profesional de las áreas afines a la disciplina. Es editada por la Facultad de Diseño y el Centro de Investigaciones (CIFAR) de la Universidad Católica de Colombia en Bogotá (Colombia).

La principal área científica a la que se adscribe la Revista de Arquitectura (Bogotá) según la OCDE es:

Gran área: 6. Humanidades

Área: 6.D. Arte

\section{Disciplina: 6D07. Arquitectura y Urbanismo}

También se publican artículos de las disciplinas como 2A02, Ingeniería arquitectónica; 5G03, Estudios urbanos (planificación y desarrollo); 6D07, Diseño.

Los objetivos de la Revista de Arquitectura (Bogotá) son:

- Promover la divulgación y difusión del conocimiento generado a nivel local, nacional e internacional

- Conformar un espacio para la construcción de comunidades académicas y la discusión en torno a las secciones definidas.

- Fomentar la diversidad institucional y geográfica de los autores que participan en la publicación.

- Potenciar la discusión de experiencias e intercambios científicos entre investigadores y profesionales.

- Contribuir a la visión integral de la arquitectura, por medio de la concurrencia y articulación de las secciones mediante la publicación de artículos de calidad.

- Publicar artículos originales e inéditos que han pasado por revisión de pares, para asegurar que se cumplen las normas éticas, de calidad, validez científica, editorial e investigativa.

- Fomentar la divulgación de las investigaciones y actividades desarrolladas en la Universidad Católica de Colombia.
Palabras clave de la Revista de Arquitectura (Bogotá): arquitectura, diseño, educación arquitectónica, proyecto y construcción, urbanismo.

Idiomas de publicación: español, inglés, portugués y francés. Título abreviado: Rev. Arquit.

\section{Titulo corto: RevArq}

\section{Políticas de sección}

La revista se estructura en tres secciones correspondientes a las líneas de investigación activas y aprobadas por la institución, y dos complementarias, que presentan dinámicas propias de la Facultad de Diseño y las publicaciones relacionadas con la disciplina.

Cultura y espacio urbano. En esta sección se publican los artículos que se refieren a fenómenos sociales en relación con el espacio urbano, atendiendo aspectos de la historia, el patrimonio cultural y físico, y la estructura formal de las ciudades y el territorio.

Proyecto arquitectónico y urbano. En esta sección se presentan artículos sobre el concepto de proyecto, entendido como elemento que define y orienta las condiciones proyectuales que devienen en los hechos arquitectónicos o urbanos, y la forma como estos se convierten en un proceso de investigación y nuevo de conocimiento. También se presentan proyectos que sean resultados de investigación, los cuales se validan por medio de la ejecución y transformación en obra construida del proceso investigativo. También se contempla la publicación de investigaciones relacionadas con la pedagogía y didáctica de la arquitectura, el urbanismo y el diseño.

Tecnología, medioambiente y sostenibilidad. En esta sección se presentan artículos acerca de sistemas estructurales, materiales y procesos constructivos, medioambiente y gestión, relacionados con los entornos social-cultural, ecológico y económico.

Desde la Facultad. En esta sección se publican artículos generados en la Facultad de Diseño, relacionados con las actividades de docencia, extensión, formación en investigación o internacionalización, las cuales son reflejo de la dinámica y de las actividades realizadas por docentes, estudiantes y egresados; esta sección no puede superar el $20 \%$ del contenido.

Textos. En esta sección se publican reseñas, traducciones y memorias de eventos relacionados con las publicaciones en Arquitectura y Urbanismo.

\section{A Frecuencia de publicación}

Desde 1999 y hasta el 2015, la Revista de Arquitectura (Bogotá) publicó un volumen al año, a partir del 2016 se publicarán dos números por año en periodo anticipado, enero-junio y julio-diciembre, pero también maneja la publicación anticipada en línea de los artículos aceptados (versión Post-print del autor).

La Revista de Arquitectura (Bogotá) se divulga mediante versiones digitales (PDF, HTML, EPUB, XML) e impresascon un tiraje de 700 ejemplares, los tiempos de producción de estas versiones dependerán de los cronogramas establecidos por la editorial.

Los tiempos de recepción-revisión-aceptación pueden tardar entre seis y doce meses dependiendo del flujo editorial de cada sección y del proceso de revisión y edición adelantado.

Con el usuario y contraseña asignados, los autores pueden ingresar a la plataforma de gestión editorial y verificar el estado de revisión, edición o publicación del artículo.
A Canje

La Revista de Arquitectura (Bogotá) está interesada en establecer canje con publicaciones académicas, profesionales o científicas del área de Arquitectura y Urbanismo, como medio de reconocimiento y discusión de la producción científica en el campo de acción de la publicación.

\section{Mecanismo}

Para establecer canje por favor descargar, diligenciar y enviar el formato: RevArq FP20 Canjes

\section{Universidad Católica de Colombia (2019, enero-junio). Revista de Arquitectura (Bogotá), $2 I(\mathrm{I})$ I-120. Doi: 10.14718 \\ ISSN: 1657-0308 E-ISSN: 2357-626X \\ Especificaciones: Formato: $34 \times 24 \mathrm{~cm}$ Papel: Mate $115 \mathrm{~g}$ Tintas: Negro y policromía}

A Contacto

Dirección postal:

Avenida Caracas No. 46-72.

Universidad Católica de Colombia

Bogotá D.C.(Colombia)

Código postal: 111311

Facultad de Diseño

Centro de Investigaciones (CIFAR).

Sede El Claustro. Bloque "L", 4 piso

Diag. 46a No. 15b-10

Editor, Arq. César Eligio-Triana

Teléfonos:

+57 (1) $3277300-3277333$

Ext. $3109 ; 3112$ o 5146

Fax: +57 (1) 2858895
Correo electrónico:

revistadearquitectura@ucatolica.edu.co

cifar@ucatolica.edu.co

Página WEB:

www.ucatolica.edu.co

vínculo Revistas científicas

http://publicaciones.ucatolica.edu.co revistas-cientificas

http://editorial.ucatolica.edu.co/ojsucatolica/revistas_ucatolica/index.php/RevArq 
Universidad Católica de Colombia

Presidente

Édgar Gómez Betancourt

Vicepresidente - Rector

Francisco José Gómez Ortiz

Vicerrector Jurídico

Edwin de Jesús Horta Vásquez

Vicerrector Administrativo

Édgar Gómez Ortiz

Vicerrector Académico

Elvers Medellín Lozano

Vicerrector de Talento Humano

Ricardo López Blum

Director de Investigaciones

Edwin Daniel Durán Gaviria

Directora Editorial

Stella Valbuena García

\section{Facultad de Diseño}

Decano

Werner Gómez Benítez

Director de docencia

Jorge Gutiérrez Martínez

Directora de extensión

Mayerly Rosa Villar Lozano

Director de investigación

Hernando Verdugo Reyes

Director de gestión de calidad

Augusto Forero La Rotta

Comité asesor externo

Facultad de Diseño

Édgar Camacho Camacho

Martha Luz Salcedo Barrera

Samuel Ricardo Vélez
Facultad de Diseño

Centro de Investigaciones - CIFAR

\section{REVISTA DE ARQUITECTURA \\ Revista de Arquitectura \\ (Bogotá)}

Revista de acceso abierto,

arbitrada e indexada

Publindex: Categoría B. Índice Bibliográfico Nacional IBN.

Esci: Emerging Source Citation Index.

Doaj: Directory of Open Access Journals.

Redalyc: Red de Revistas Cientificas de América Latina y el Caribe,

España y Portugal.

SciELO: Scientific Electronic Library Online - Colombia

Redib: Red Iberoamericana de Innovación y Conocimiento Cientifico.

Ebsco: EBSCOhost Research Databases.

Clase: Base de datos bibliográfica de revistas de ciencias sociales y

humanidades.

Latindex: Sistema Regional de Información en Línea para Revistas

Científicas de América Latina, el Caribe, España y Portugal (Directorio

y catálogo).

Dialnet: Fundación Dialnet - Biblioteca de la Universidad de La Rioja.

LatinRev: Red Latinoamericana de Revistas Académicas en Ciencias

Sociales $y$ Humanidades.

Proquest: ProQuest Research Library.

Miar: Matrix for the Analysis of Journals.

Sapiens Research: Ranking de las mejores revistas colombianas según

visibilidad internacional.

Actualidad Iberoamericana: (Índice de Revistas) Centro de Información

Tecnológica (CIT).

Google Scholar

Arla: Asociación de Revistas latinoamericanas de Arquitectura.

\section{Editorial}

Av. Caracas $N^{\circ} 46-72$, piso 5

Teléfono: 3277300 Ext. 5145

editorial@ucatolica.edu.co

www.ucatolica.edu.co

http://publicaciones.ucatolica.edu.co/

Impresión:

JaVEGRAF

Calle 46A No82-54 Int. 2

Bogotá, D. C., Colombia

http://www.javegraf.com.co/index.php

Enero de 2019
Director

Werner Gómez Benítez

Editor

César Eligio-Triana

Editores de sección

(1) Myriam Stella Díaz-Osorio

(1) Carolina Rodríguez-Ahumada

(1) Anna Maria Cereghino-Fedrigo

\section{Equipo editorial}

Coordinadora editorial

María Paula Godoy Casasbuenas

mpgodoy@ucatolica.edu.co

Diseño y montaje

Juanita Isaza

juanaisaza@gmail.com

Traductoras

Inglés

Erika Tanacs

etanacs25@gmail.com

Portugués

Roanita Dalpiaz

roanitad@gmail.com

Correctora de estilo

María José Díaz Granados M.

mariajose_dgm@yahoo.com.co

Página Web

Centro de investigaciones (CIFAR)

Distribución y canjes

Claudia Álvarez Duquino

calvarez@ucatolica.edu.co
Comité editorial y científico

Cultura y espacio urbano

Carlos Mario Yory, PhD

Universidad Católica de Colombia. Bogotá, Colombia

Sonia Berjman, $\mathrm{PhD}$

ICOMOS-IFLA, Buenos Aires, Argentina

Juan Carlos Pérgolis, MSc Universidad Piloto de Colombia. Bogotá, Colombia

Beatriz García Moreno, PhD

Universidad Nacional de Colombia. Bogotá, Colombia

Proyecto arquitectónico y urbano

A Jean-Philippe Garric, PhD, HDR

Université Paris I Panthéon-Sorbonne. Paris, Francia

Debora Domingo Calabuig, PhD

Universidad Politécnica de Valencia, España

Dania González Couret, PhD

Universidad Tecnológica de La Habana, Cuba

Hugo Mondragón López, PhD Pontificia Universidad Católica de Chile. Santiago, Chile

Juan Pablo Duque Cañas, PhD

Universidad Nacional de Colombia. Bogotá, Colombia

Tecnología, medioambiente y sostenibilidad

Mariano Vázquez Espí, PhD

Universidad Politécnica de Madrid, España

Denise Helena Silva Duarte, PhD Universidade de São Paulo (USP), Brasil

Luis Carlos Herrera Sosa, PhD Universidad Autónoma de Ciudad Juárez, México

Claudio Varini, PhD

Universidad Católica de Colombia. Bogotá, Colombia

Luis Gabriel Gómez Azpeitia, PhD Universidad de Colima. Colima, México 


\section{CONTENDO}
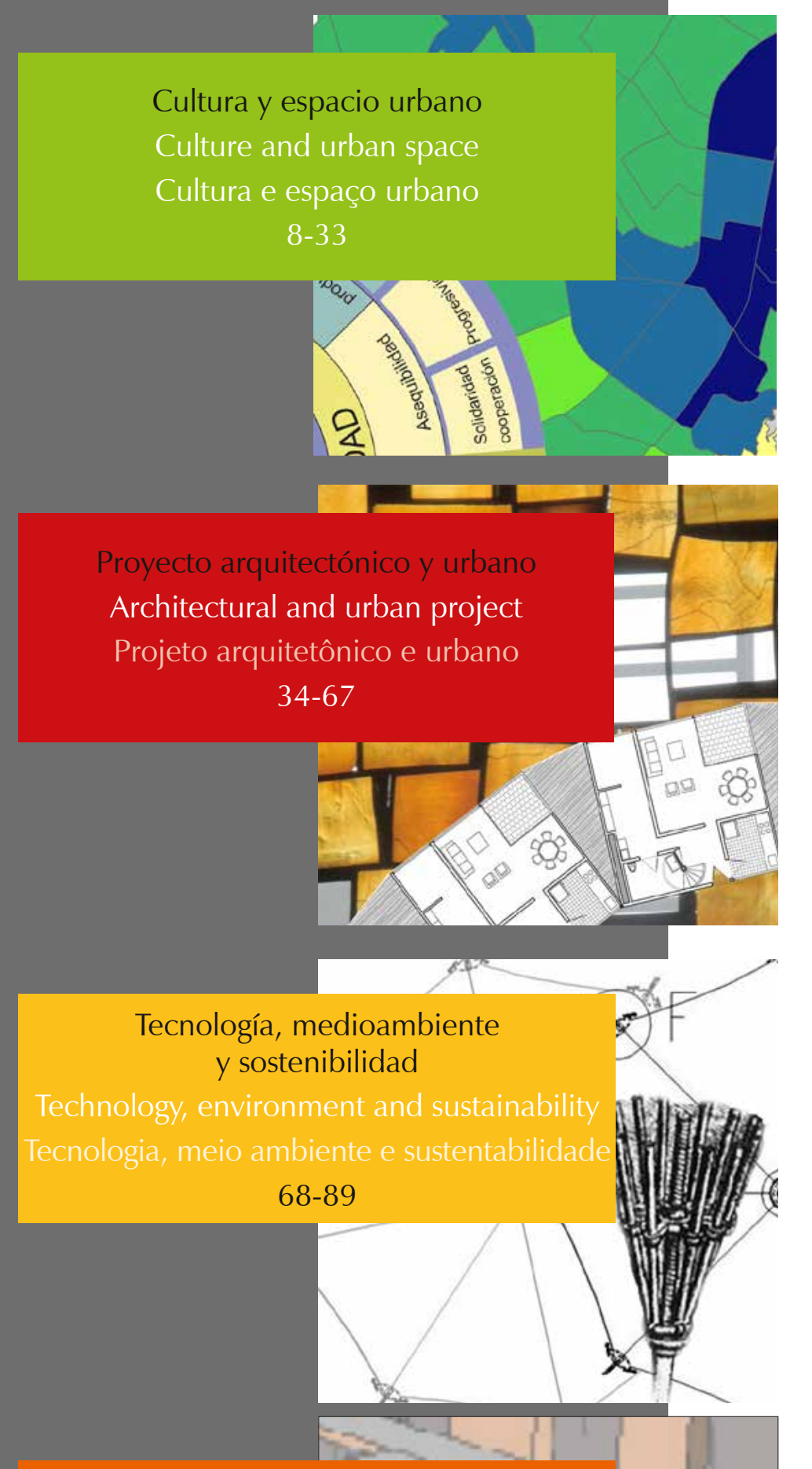

Desde la Facultad

From the Faculty

Da faculdade

90-109
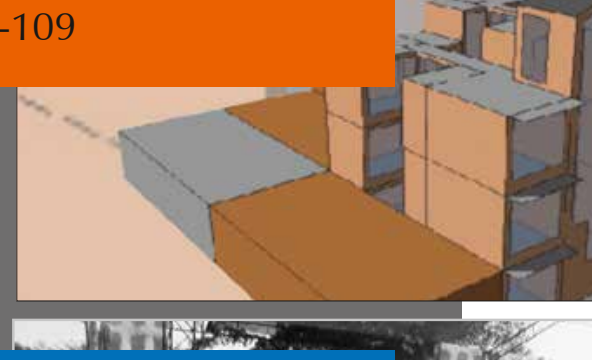

Textos

Texts

Textos

110-118
Revistas en tiempos tecno-humanos

Julio Arroyo

Pág. 3

ES

Índice de caminabilidad para la ciudad de Bogotá

Julián Alberto Gutiérrez-López
Yolanda Beatriz Caballero-Pérez
Rubén Alejandro Escamilla-Triana

ES

Pág. 8

Principios, criterios y propósitos de desarrollo sustentable para la redensificación en contextos urbanos informales
Juan José Castiblanco-Prieto
Fabián Adolfo Aguilera-Martínez
Fabián Alonso Sarmiento-Valdés

Pág. 21

ES

Complejidad y constructivismo en la nueva tradición de la arquitectura de la posguerra

Francisco Javier Fuentes-Farías

Pág. 34 ES

Conservación del arte contemporáneo

El caso de Mathias Goeritz en la Catedral

Metropolitana de México

Alberto Cedeño-Valdiviezo

Pablo Torres-Lima

Pág. 44

\section{ES EN}

Operando desde la forma: un procedimiento

para la valoración de la vivienda colectiva

Julián Camilo Valderrama-Vidal

Pág. 54

ES

Disponibilidad de las técnicas constructivas

de habitación en madera, en Brasil

Victor A. De Araujo

Carlos M. Gutiérrez-Aguilar

Juliana Cortez-Barbosa

Maristela Gava

José N. Garcia

Pág. 68

ES

Diseño y construcción de un paraguas plegable para espacios arquitectónicos

Carlos César Morales-Guzmán

Pág. 76

ES EN

Envolventes eficientes

Relación entre condiciones ambientales, espacios confortables

y simulaciones digitales

Natalia Medina-Patrón

Jonathan Escobar-Saiz

Pág. 90

ES

(Re)pensando el enfoque tecnológico:

el caso del Centro Experimental de la Vivienda

Económica (CEVE) en Argentina

Gustavo Pelegrin

Laila Fleker

Aurelio Ferrero

Pág.110 
La postulación de un artículo a la Revista de Arquitectura (Bogotá) indica que- el o los autores certifican que conocen y aceptan la política editorial, para lo cual firmarán en original y remitirán el formato RevArq FP00 Carta de originalidad.

La Revista de Arquitectura (Bogotá) maneja una política de Autoarchivo VERDE, según las directrices de SHERPA/RoMEO, por lo cual el autor puede:

- Pre-print del autor: Archivar la versión pre-print (la versión previa a la revisión por pares

- Post-print del autor: Archivar la versión post-print (la versión final posterior a la revisión por pares

- Versión de editor/PDF: Archivar la versión del editor - PDF/HTML/XLM en la maqueta de la Revista de Arquitectura (Bogotá).

El Autoarchivo se debe hacer respetando la licencia de acceso abierto, la integridad y la imagen de la Revista de Arquitectura (Bogotá), también se recomienda incluir la referencia, el vínculo electrónico y el DOI.

El autor o los autores son los titulares del Copyright (c) del texto publicado y la Editorial de la Revista de Arquitectura (Bogotá) solicita la firma de una autorización de reproducción del artículo (RevArq FP03 Autorización reproducción), la cual se acoge a la licencia CC, donde se expresa el derecho de primera publicación de la obra.

La Revista de Arquitectura (Bogotá) se guía por las normas internacionales sobre propiedad intelectual y derechos de autor, y de manera particular el artículo 58 de la Constitución Política de Colombia, la Ley 23 de 1982 y el Acuerdo 172 del 30 de septiembre de 2010 (Reglamento de propiedad intelectual de la Universidad Católica de Colombia)

Para efectos de autoría y coautoría de artículos se diferencian dos tipos: "obra en colaboración" y "obra colectiva". La primera es aquella cuya autoría corresponde a todos los participantes al ser fruto de su trabajo conjunto. En este caso, quien actúa como responsable y persona de contacto debe asegurar que quienes firman como autores han revisado y aprobado la versión final, y dan consentimiento para su divulgación. La obra colectiva es aquella en la que, aunque participan diversos colaboradores, hay un autor que toma la iniciativa la coordinación y realización de dicha obra. En estos casos, la autoría corresponderá a dicha persona (salvo pacto en contrario) y será suficiente únicamente con su autorización de divulgación.

El número de autores por artículo debe estar justificado por el tema, la complejidad y la extensión, y no deberá ser superior a la media de la disciplina, por lo cual se recomienda que no sea mayor de cinco. El orden en que se enuncien corresponderá a los aportes de cada uno a la construcción del texto, se debe evitar la autoría ficticia o regalada. Si se incluyen más personas que trabajaron en la investigación se sugiere que sea en calidad de colaboradores o como parte de los agradecimientos. La Revista de Arquitectura (Bogotá) respetará el número y el orden en que figuren en el original remitido. Si los autores consideran necesario, al final del artículo pueden incluir una breve descripción de los aportes individuales de cada uno de firmantes.

La comunicación se establece con uno de los autores, quien a su vez será el responsable de informar a los demás autores de las notificaciones emitidas por la Revista de Arquitectura (Bogotá).

En virtud de mantener el equilibro de las secciones y las mismas oportunidades para todos los participantes, un mismo autor puede postular dos o más artículos de manera simultánea; si la decisión editorial es favorable y los artículos son aceptados, su publicación se realizará en números diferentes.

\section{A Acceso abierto}

La Revista de Arquitectura (Bogotá), en su misión de divulgar la investigación y apoyar el conocimiento y la discusión en los campos de interés, proporciona acceso abierto, inmediato e irrestricto a su contenido de manera gratuita mediante la distribución de ejemplares impresos y digitales. Los interesados pueden leer, descargar, guardar, copiar y distribuir, imprimir, usar, buscar o referenciar el texto completo o parcial de los artículos o la totalidad de la Revista de Arquitectura (Bogotá).

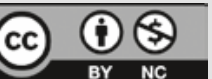

Esta revista se acoge a la licencia Creative Commons (CC BY NC de Atribución - No comercial 4.0 Internacional): "Esta licencia permite a otros entremezclar, ajustar y construir a partir de su obra con fines no comerciales, y aunque en sus nuevas creaciones deban reconocerle su autoría y no puedan ser utilizadas de manera comercial, no tienen que estar bajo una licencia con los mismos términos".

La Revista de Arquitectura es divulgada en centros y grupos de investigación, en bibliotecas y universidades, y en las principales facultades de Arquitectura mediante acceso abierto a la versión digital y suscripción anual al ejemplar impreso o por medio de canje, este último se formaliza mediante el formato RevArq FP20 Canjes

Para aumentar su visibilidad y el impacto de los artículos, se envían a bases de datos y sistemas de indexación y resumen (SIR) y, asimismo, pueden ser consultados y descargados en la página web de la revista.

La Revista de Arquitectura no maneja cobros, tarifas o tasas de publicación de artículo (Article Processing Charge-APC), o por el sometimiento de textos a la publicación.

\section{(1)Ética y buenas prácticas}

La Revista de Arquitectura se compromete a cumplir y respetar las normas éticas en todas las etapas del proceso de publicación. Los autores de los artículos publicados darán cumplimiento a los principios éticos contenidos en las diferentes declaraciones y legislaciones sobre propiedad intelectual y derechos de autor específicos del país donde se realizó la investigación. En consecuencia, los autores de los artículos postulados y aceptados para publicar, que presentan resultados de investigación, deben firmar la declaración de originalidad (formato RevArq FP00 Carta de originalidad).

La Revista de Arquitectura reconoce y adopta los principios de transparencia y buenas prácticas descritos por COPE, "Principles of Transparency and Best Practice in Scholarly Publishing" (2015).

El equipo editorial tiene la obligación de guardar la confidencialidad acerca de los artículos recibidos, y abstenerse de usar en sus propias investigaciones datos, argumentos o interpretaciones hasta tanto el artículo no sea publicado. También debe ser imparcial y gestionar los artículos de manera adecuada y en los plazos establecidos. La selección de revisores se hará con objetividad y estos deberán responder a la temática del artículo.

El editor, los autores y los revisores deben seguir las normas éticas internacionales definidas por el Committee on Publication Ethics (COPE), con el fin de evitar casos de:

- Fabricación, falsificación u omisión de datos.

- Plagio y autoplagio.

- Publicación redundante, duplicada o fragmentada.

- Omisión de referencias a las fuentes consultadas.

- Utilización de contenidos sin permiso o sin justificación.

- Apropiación individual de autoría colectiva.

- Cambios de autoría.

- Conflicto de interés (CDI) no revelado o declarado.

- Otras que pudieran surgir en el proceso de investigación y publicación. La fabricación de resultados se genera al mostrar datos inventados por los autores; la falsificación resulta cuando los datos son manipulados y cambiados a capricho de los autores; la omisión se origina cuando los autores ocultan deliberadamente un hecho o dato. El plagio se da cuando un autor presenta como ideas propias datos creados por otros. Los casos de plagio son los siguientes: copia directa de un texto sin entrecomillar o citar la fuente, modificación de algunas palabras del texto, paráfrasis y falta de agradecimientos; el autoplagio se da cuando el mismo autor reutiliza material propio que ya fue publicado, pero sin indicar la referencia al trabajo anterior. La revista se apoya en herramientas digitales que detectan cualquiera de estos casos en los artículos postulados, y es labor de los editores y revisores velar por la originalidad y fidelidad en la citación. La publicación redundante o duplicada se refiere a la copia total, parcial o alterada de un trabajo ya publicado por el mismo autor

En caso de sospechar de alguna mala conducta se recomienda seguir los diagramas de flujo elaborados por COPE (2008), con el fin de determinar las acciones correspondientes.

La Revista de Arquitectura se reserva el derecho de retractación de publicación de aquellos artículos que, posterior a su publicación, se demuestre que presentan errores de buena fe, o cometieron fraudes o malas prácticas científicas. Esta decisión se apoyará en "Retraction Guidelines" (COPE, 2009). Si el error es menor, este se podrá rectificar mediante una nota editorial de corrección o una fe de erratas. Los autores también tienen la posibilidad de solicitar la retractación de publicación cuando descubran que su trabajo presenta errores graves. En todos los casos se conservará la versión electrónica y se harán las advertencias de forma clara e inequívoca.

\section{A Privacidad y manejo de la información.} Habeas Data

Para dar cumplimiento a lo previsto en el artículo 10 del Decreto 1377 de 2013, reglamentario de la Ley 1581 de 2012, y según el Acuerdo 002 del 4 de septiembre de 2013 de la Universidad Católica de Colombia, "por el cual se aprueba el manual de políticas de tratamiento de datos personales":

La Universidad Católica de Colombia, considerada como responsable o encargada del tratamiento de datos personales, manifiesta que los datos personales de los autores, integrantes de los comités y pares revisores, se encuentran incluidos en nuestras bases de datos; por lo anterior, y en cumplimiento de las disposiciones legales vigentes, la Universidad solicitará siempre su autorización, para que en desarrollo de sus funciones propias como Institución de Educación Superior, en especial las relacionadas con la docencia, la extensión y la investigación, la Universidad Católica de Colombia pueda recolectar, recaudar, almacenar, usar, circular, suprimir, procesar, intercambiar, compilar, dar tratamiento, actualizar, transmitir o transferir a terceros países y disponer de los datos que le han suministrado y que han sido incorporados en las bases de datos de todo tipo que reposan en la Universidad.

La Universidad Católica de Colombia queda autorizada, de manera expresa e inequívoca, en los términos señalados por el Decreto 1377 de 2013, para mantener y manejar la información de nuestros colaboradores (autores, integrantes de los diferentes comités y pares revisores); así mismo, los colaboradores podrán ejercer sus derechos a conocer, actualizar, rectificar y suprimir sus datos personales, para lo cual se han dispuesto las siguientes cuentas de correo electrónico: 
La Revista de Arquitectura (Bogotá) recibe artículos de manera permanente. Los artículos se procesan a medida que se postulan, dependiendo el flujo editorial de cada sección.

El idioma principal es el español, y como opcionales están definidos el inglés, el portugués y el francés; los textos pueden ser escritos y presentados en cualquiera de estos.

Los artículos postulados deben corresponder a las categorías universalmente aceptadas como producto de investigación, ser originales e inéditos y sus contenidos responder a criterios de precisión, claridad y brevedad.

Como punto de referencia se pueden tomar las tipologías y definiciones del Îndice Bibliográfico Nacional, Publindex (2010) que se describen la continuación:

1. Artículo de revisión: documento resultado de una investigación terminada donde se analizan, sistematizan e integran los resultados de investigaciones publicadas o no publicadas, sobre un campo en ciencia o tecnología, con el fin de dar cuenta de los avances y las tendencias de desarrollo. Se caracteriza por presentar una cuidadosa revisión bibliográfica de por lo menos 50 referencias.
2. Artículo de investigación científica y tecnológica: documento que presenta, de manera detallada, los resultados originales de proyectos terminados de investigación. La estructura generalmente utilizada contiene cuatro apartes importantes: introducción, metodología, resultados y conclusiones.

3. Artículo de reflexión: documento que presenta resultados de investigación terminada desde una perspectiva analítica, interpretativa o crítica del autor, sobre un tema específico, recurriendo a fuentes originales.

Adicional a estas tipologías, se pueden presentar otro tipo de artículos asociados a procesos de investigación-creación y/o investigación proyectual. En todos los casos se debe presentar la información suficiente para que cualquier investigador pueda reproducir la investigación y confirmar o refutar las interpretaciones defendidas y sea evidente el aporte a la disciplina.

En todos los casos se debe presentar la información suficiente para que cualquier investigador pueda reproducir la investigación y confirmar o refutar las interpretaciones defendidas.

\section{(A) Instrucciones para postular artículos}

Postular el artículo en la página web de la Revista de Arquitectura (Bogotá) y adjuntar comunicación escrita dirigida al editor RevArq_FP00 Carta de originalidad (debidamente firmada por todos los autores en original); de igual manera, se debe diligenciar el formato de hoja de vida RevArq FP01 Hoja de Vida (una por cada autor).

En la comunicación escrita el autor expresa que conoce y acepta la política editorial de la Revista de Arquitectura (Bogotá), que el artículo no está postulado para publicación simultáneamente en otras revistas u órganos editoriales y que no existe conflicto de intereses (ver modelo RevArq FP06 CDI) y que, de ser aceptado, concederá permiso de primera publicación, no exclusiva a nombre de la Universidad Católica de Colombia como editora de la revista.

Los artículos deben tener en cuenta las siguientes recomendaciones:

- En la primera página del documento se debe incluir:

Tírulo: no exceder 15 palabras

Subtítulo: opcional, complementa el título o indica las principales subdivisiones del texto.

Nombre del autor o autores: nombres y apellidos completos o según modelo de citación adoptado por el autor para la normalización de los nombres del investigador. Como nota al pie (máximo 100 palabras) formación académica, experiencia profesional e investigativa, código ORCID https://orcid.org/, e información de contacto, correo electrónico.

Filiación institucional: debajo del nombre se debe declarar la ins-titución en la cual se desarrolló el producto, de la cual recibió apoyo o aquella que respalda el trabajo investigativo.

Resumen: debe ser analítico, se redacta en un solo párrafo, da cuenta del tema, el objetivo, la metodología, los resultados y las conclusiones; no debe exceder las 150 palabras.

Palabras clave: cinco palabras o grupo de palabras, ordenadas alfabéticamente y que no se encuentren en el título o subtítulo; estas sirven para clasificar temáticamente al artículo. Se recomienda emplear principalmente palabras definidas en el tesauro de la Unesco (http://databases. unesco.org/thessp/), en el tesauro de Arte \& Arquitectura (C) (www.aatespanol.cl), o Vitruvio (http://vocabularyserver.com/vitruvio/)

También se recomienda incluir título, resumen y palabras clave en segundo idioma.

- La segunda página y siguientes deben tener en cuenta:

El cuerpo del artículo se divide en: Introducción, Metodología, Resultados y Discusión de resultados; posteriormente se presentan las Conclusiones, y luego las Referencias bibliográficas y los Anexos (modelo IMRYD). Las tablas y figuras se deben incorporar en el texto.

Descripción del proyecto de investigación: en la introducción se debe describir el tipo de artículo y brevemente el marco investigativo del cual es resultado y diligenciar el formato (RevArq FP02 Info Proyectos de Investigación).

TEXTO: todas las páginas deben venir numeradas y con el título de artículo en la parte superior de la página. Márgenes de $3 \mathrm{~cm}$ por todos los lados, interlineado doble, fuente Arial o Times New Roman de 12 puntos, texto justificado (Ver plantilla para presentación de artículos). La extensión de los artículos debe ser de alrededor de 5.000 palabras ( \pm 20 páginas, incluyendo gráficos, tablas, referencias, etc.); como mínimo 3.500 y máximo 8.000 palabras. Se debe seguir el estilo vigente y recomendado en el Manual para Publicación de la American Psychological Association (APA). (Para mayor información véase http://www.apastyle.org/)
Citas y notas al pie: las notas aclaratorias o notas al pie no deben exceder cinco líneas o 40 palabras, de lo contrario estas deben ser incorporadas al texto general. Las citas pueden ser:

Corta: (con menos de 40 palabras) se incorporan al texto y pueden ser: textuales (se encierran entre dobles comillas), parafraseo o resumen (se escriben en palabras del autor dentro del texto).

Cita textual extensa: (mayor de 40 palabras) debe ser dispuesta en un renglón y un bloque independiente con sangrías y omitiendo las comillas, no olvidar en ningún caso la referencia del autor (Apellido, año, página).

Referencias: como modelo para la construcción de referencias se emplea el estilo recomendado en el Manual para Publicación de la American Psychological Association (APA) (http://www.apastyle.org/).

Siglas: en caso de emplear siglas en el texto, las figuras o las tablas, se debe proporcionar la equivalencia completa la primera vez que se empleen y encerrarlas entre paréntesis. En el caso de citar personajes reconocidos se deben colocar nombres o apellidos completos, nunca emplear abreviaturas.

Figuras y tablas: las figuras (gráficos, diagramas, ilustraciones, planos, mapas o fotografías) y las tablas deben ir numeradas y contener título o leyenda explicativa relacionada con el tema del artículo, que no exceda las 15 palabras (Figura 1. xxxxx, Tabla 1. xxxx, etc.) y la procedencia (fuente: autor o fuente, año, página). Estas se deben referenciar en el texto de forma directa o entre paréntesis; se recomienda hacerlo con referencias cruzadas.

También se deben entregar en medio digital, independiente del texto, en formatos editables o abiertos. La marcación de los archivos debe corresponder a la incluida en el texto. Según la extensión del artículo se deben incluir de 5 a 10 gráficos. Ver guía para la búsqueda de imágenes de dominio público o bajo licencias Creative Commons (CC).

El autor es el responsable de adquirir los derechos o las autorizaciones de reproducción a que haya lugar para imágenes o gráficos tomados de otras fuentes, así como de entrevistas o material generado por colaboradores diferentes a los autores; de igual manera, se debe garantizar la protección de datos e identidades para los casos que sea necesario.

FotografíA: pueden ser entregadas en original para ser digitalizadas, de lo contrario se deben digitalizar con una resolución igual o superior a 300 dpi para imágenes a color y 600 para escala de grises. Los formatos de las imágenes pueden ser TIFF, PSD o JPG, y deben cumplir con las características expresadas en el punto anterior (figuras).

Planimetría: se debe entregar la planimetría original en medio digital, en lo posible en formato CAD, y sus respectivos archivos de plumas o en PDF; de no ser posible, se deben hacer impresiones en tamaño carta con las referencias de los espacios mediante numeración y lista adjunta. Deben tener escala gráfica, escala numérica, norte, coordenadas y localización. En lo posible, no deben contener textos, achurados o tramas.

Para más detalles, consultar el documento RevArq Parámetros para Autores Descripción en el portal web de la Revista de Arquitectura (Bogotá)

\section{Beneficios}

Como reconocimiento a los autores, se les hará envío postal de dos ejemplares de la edición impresa sin ningún costo y entregada en la dirección consignada en el formato de hoja de vida (RevArq FP01); adicionalmente, se enviará el vínculo para la descarga de la versión digital.

También se enviará una constancia informativa en la que se relaciona la publicación del artículo y, de manera opcional, se pueden detallar las fechas del proceso editorial y el arbitraje realizado. 
La selección de revisores se realiza de acuerdo con los siguientes criterios:

- Afinidad temática.

- Formación académica.

- Experiencia investigativa y profesional.

- Producción editorial en revistas similares o en libros resultado de investigación.

El proceso de arbitraje se basa en los principios de equidad e imparcialidad, y en los criterios de calidad y pertinencia.

El desarrollo de la revisión se realiza según el formato (RevArq FP10 Evaluación de artículos) y las observaciones que el revisor considere necesarias en el cuerpo del artículo. En cualquiera de los conceptos que emita el revisor (Aceptar, Publicable con modificaciones, Reevaluable o No publicable), y como parte de la labor formativa y de comunidad académica, el revisor hará sugerencias para mejorar et documento. El revisor podrá solicitar una nueva relectura del artículo después de los ajustes realizados por el autor.

El revisor también deberá diligenciar el formato RevArq FP01 Hoja de Vida, con el fin de certificar y soportar el proceso de revisión ante los SIR que así lo soliciten.

En el proceso de arbitraje se emplea el método doble ciego, los nombres del revisor no serán conocidos por el autor y viceversa. Con el fin de garantizar el anonimato del autor, al artículo postulado se le han podido suprimir nombres, instituciones o imágenes que puedan ser asociadas de manera directa al autor.

Aunque se procura el anonimato, una vez recibida la invitación como par revisor del artículo, el revisor debe cerciorarse de que no exista conflicto de intereses (CDI) o alguna limitante que afecte la revisión o que pueda ser vista como tal (lazos familiares, amistad o enemistad, vínculos contractuales o laborales, posiciones éticas, etc.), de presentarse esta situación se notificara al editor. (Ver modelo RevArq FP06 CDI).

Dada la confidencialidad del proceso de revisión, y considerando los derechos de autor y de propiedad intelectual que pueda haber sobre el material que se entrega, el revisor se compromete a mantener en absoluta reserva su labor, a limitar el uso de la obra entregada solo para el propósito designado y a devolver la documentación remitida una vez concluya la actividad.

El tiempo establecido para las revisiones de pares es de máximo un mes a partir de la confirmación de la recepción de la documentación. Ese plazo podrá ser modificado de mutuo acuerdo entre e editor y el revisor, siempre y cuando no afecte la periodicidad de la revista, la impresión o el tiempo para emitir una respuesta al autor.

Los revisores se acogerán a "COPE Ethical Guidelines for Peer Reviewers" de COPE.

\section{Beneficios}

Como retribución a los revisores se les hará envío postal de un ejemplar de la edición impresa sin ningún costo y entregada en la dirección consignada en el formato de hoja de vida. También, si es de interés para el revisor, podrá hacer la solicitud de alguna de las publicaciones editadas y presentes en el catálogo de publicaciones de la UNIVERSIDAD CATÓLICA DE COLOMBIA, previa aprobación de la Editorial y sujeto a la disponibilidad.

Si lo desea tendrá derecho a una constancia de la colaboración en la revisión de artículos, la cual solo contendrá el periodo en el cual se realizó la actividad. También tendrá la posibilidad de aceptar o no la publicación de su nombre, nacionalidad y nivel máximo de formación en la página web de la Revista de Arquitectura (Bogotá) en su calidad de colaborador.

\section{A Proceso de revisión por pares}

Luego de la postulación del artículo, el editor de la Revista de Arquitectura (Bogotá) selecciona y clasifica los artículos que cumplen con los requisitos establecidos en las directrices para los autores. El editor podrá rechazar en primera instancia artículos, sin recurrir a un proceso de revisión, si los considera de baja calidad o por presentar evidencias de faltas éticas o documentación incompleta.

Los artículos se someterán a un primer dictamen del editor, de los editores de sección y del Comité Editorial, teniendo en cuenta:

- Afinidad temática, relevancia del tema y correspondencia con las secciones definidas.

- Respaldo investigativo.

- Coherencia en el desarrollo del artículo, así como una correcta redacción y ortografía.

- Relación entre las figuras y tablas con el texto del artículo.
En esta revisión se verificará el nivel de originalidad mediante el uso de software especializado (Ithenticate o similar) y recursos digitales existentes para tal fin, también se observará la coherencia y claridad en los apartados del documento (modelo IMRYD), la calidad de las fuentes y la adecuada citación, esto quedará consignado en el formato (RevArq FP09 Revisión de artículos); esta información será cargada a la plataforma de gestión editorial y estará a disposición del autor.

En caso de que el artículo requiera ajustes preliminares, será devuelto al autor antes de ser remitido a revisores. En este caso, el autor tendrá veinte días para remitir nuevamente el texto con los ajustes solicitados.

Después de la preselección se asignan mínimo dos revisores especializados, quienes emitirán su concepto utilizando el formato (RevArq FP10 Evaluación de artículos) y las anotaciones que consideren oportunas en el texto; en esta etapa se garantizará la confidencialidad y el anonimato de autores y revisores (modalidad doble ciego).

Del proceso de revisión se emite uno de los siguientes conceptos que será reportado al autor:

\section{- Aceptar el envío: con o sin observaciones.}

- Publicable con modificaciones: se podrá sugerir la forma más adecuada para una nueva presentación, el autor puede o no aceptar las observaciones según sus argumentos. Si las acepta, cuenta con quince días para realizar los ajustes pertinentes.

- Reevaluable: cumple con algunos criterios y debe ser corregido. Es necesario hacer modificaciones puntuales y estructurales al artículo. En este caso, el revisor puede aceptar o rechazar hacer una nueva lectura del artículo luego de ajustado.

- No publicable: el autor puede volver a postular el artículo e iniciar nuevamente el proceso de arbitraje, siempre y cuando se evidencien los ajustes correspondientes.

En el caso de presentarse diferencias sustanciales y contradictorias en los conceptos sobre la recomendación del revisor, el editor remitirá el artículo a un revisor más o a un miembro del Comité Editorial quien podrá actuar como tercer árbitro, con el fin de tomar una decisión editorial sobre la publicación del artículo.

Los autores deberán considerar las observaciones de los revisores o de los editores, y cada corrección incorporada u omitida debe quedar justificada en el texto o en una comunicación adjunta. En el caso que los autores omitan las indicaciones realizadas sin una argumentación adecuada, el artículo será devuelto y no se dará por recibido hasta que no exista claridad al respecto.

El editor respetará la independencia intelectual de los autores y a estos se les brindará el derecho de réplica en caso de que los artículos hayan sido evaluados negativamente y rechazados.

Los autores, con su usuario y contraseña, podrán ingresar a la plataforma de Gestión Editorial, donde encontrarán los conceptos emitidos y la decisición sobre el artículo.

El editor y el Comité Editorial se reservan el derecho de aceptar o no la publicación del material recibido. También se reservan el derecho de sugerir modificaciones de forma, ajustar las palabras clave o el resumen y de realizar la corrección de estilo. El autor conocerá la versión final del texto antes de la publicación oficial del mismo.

Cuando un artículo es aceptado para su publicación, el autor debe firmar la autorización de reproducción (RevArq FP03 Autorización reproducción). Para más información ver: Política de derechos de autor

\section{Notas aclaratorias:}

La Revista de Arquitectura (Bogotá) busca el equilibrio entre las secciones, motivo por el cual, aunque un artículo sea aceptado o continúe en proceso de revisión, podrá quedar aplazado para ser publicado en un próximo número; en este caso, el autor estará en la posibilidad de retirar la postulación del artículo o de incluirlo en el banco de artículos del próximo número.

El editor y los editores de sección de la Revista de Arquitectura (Bogotá) son los encargados de establecer contacto entre los autores y revisores, ya que estos procesos se realizan de manera anónima.
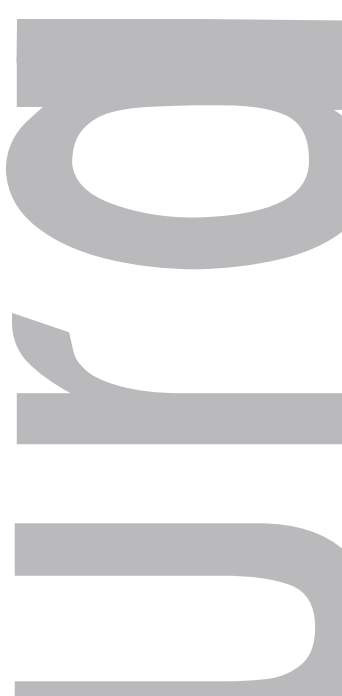
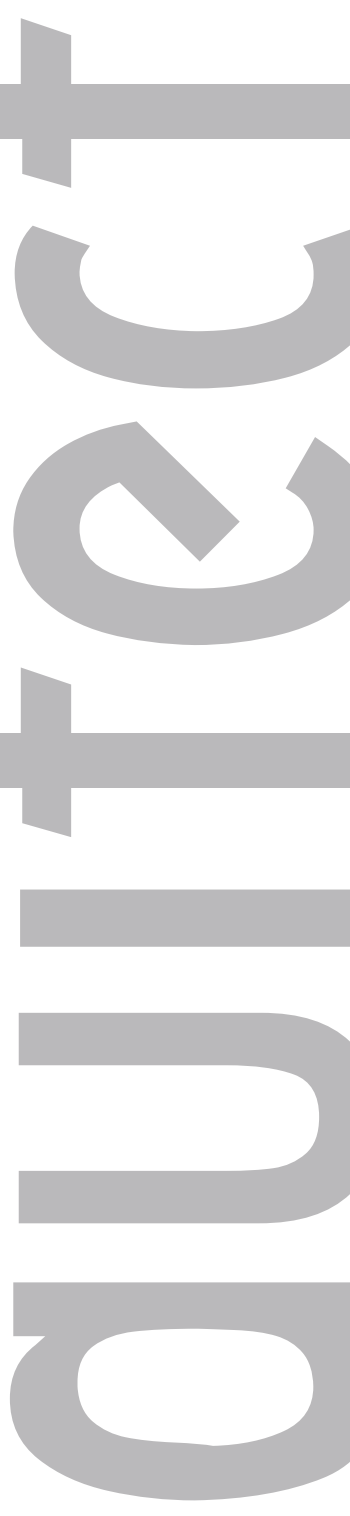

Vol. 
Índice de caminabilidad para la ciudad de Bogotá

$\infty \quad$ Walkability index for the city of Bogotá

ن Índice de caminhabilidade para a cidade de Bogotá

¿ Julián Alberto Gutiérrez-López

Yolanda Beatriz Caballero-Pérez

Rubén Alejandro Escamilla-Triana

Principios, criterios y propósitos de desarrollo sustentable para la $\bar{\sim}$ redensificación en contextos urbanos informales

$\sim$ Principles, criteria and purposes of sustainable development for

re-densification in unplanned urban contexts

Princípios, critérios e propósitos de desenvolvimento sustent

luan José Castiblanco-Prieto

Fabián Adolfo Aguilera-Martínez

Fabián Alonso Sarmiento-Valdés

Complejidad y constructivismo en la nueva tradición de la arquitectura de la posguerra

Complexity and constructivism in the new tradition of post-war architecture

U. Complexidade e construtivismo na nova tradição da arquitetura do pósguerra

Francisco Javier Fuentes-Farías

Conservación del arte contemporáneo. El caso de Mathias Goeritz en la Catedral Metropolitana de México

Conservation of contemporary art: The case of Mathias Goeritz in the

ن் Metropolitan Cathedral of Mexico

$₫ \quad$ Conservação da arte contemporânea: o caso de Mathias Goeritz na Catedral Metropolitana do México

\section{Alberto Cedeño-Valdiviezo}

Pablo Torres-Lima

Operando desde la forma: un procedimiento para la valoración de la vivienda colectiva

เก Operating based on form: A procedure for the valuation of collective housing

ن Operando a partir da forma: um procedimento para avaliar a moradia coletiva

\section{^ Julián Camilo Valderrama-Vidal}

Disponibilidad de las técnicas constructivas de habitación en madera, en Brasil

ن Availability of timber housing construction techniques in Brazil

Disonibilidade das técnicas construtivas de moradia em madeira no Brasil

\section{Victor A. De Araujo}

Carlos M. Gutiérrez-Aguilar

luliana Cortez-Barbosa

Maristela Gava

losé N. Garcia

Diseño y construcción de un paraguas plegable

* para espacios arquitectónicos

Design and construction of a folding umbrella for architectural spaces

Uั Desenho e construção de um guarda-chuva dobrável para espaços arquitetônicos

Carlos César Morales-Guzmán

Envolventes eficientes. Relación entre condiciones ambientales, espacios confortables y simulaciones digitales

Efficient building envelopes: Relationship between environmental conditions,

U. comfortable spaces, and digital simulations

Envolventes eficientes: relação entre condições ambientais, espaços confortáveis e simulações digitais

Natalia Medina-Patrón

Jonathan Escobar-Saiz

(Re)pensando el enfoque tecnológico: el caso del Centro

Experimental de la Vivienda Económica (CEVE) en Argentina

ㅇ (Re)thinking the technological approach: The case of the Experimental Center

으 for Economic Housing (CEVE) in Argentina

ن (Re)pensando a abordagem tecnológica. O caso do Centro Experimental da

Moradia Econômica na Argentina

Gustavo Pelegrin

Laila Fleker

Aurelio Ferrero 